\title{
A Novel Two-Disc Machine for High Precision Friction Assessment
}

\author{
Jakob Moder, Florian Grün, Michael Stoschka, and István Gódor \\ Chair of Mechanical Engineering, Montanuniversität Leoben, Franz-Josef-Straße 18, 8700 Leoben, Austria \\ Correspondence should be addressed to Jakob Moder; jakob.moder@unileoben.ac.at
}

Received 13 March 2017; Revised 18 May 2017; Accepted 25 May 2017; Published 28 June 2017

Academic Editor: Michael M. Khonsari

Copyright (C) 2017 Jakob Moder et al. This is an open access article distributed under the Creative Commons Attribution License, which permits unrestricted use, distribution, and reproduction in any medium, provided the original work is properly cited.

\begin{abstract}
The concept of two-disc model testing has proven to deliver valuable information for the applicability of new technologies, such as surface structuring, coatings, alternative fluids, or advanced materials, in actual machine elements. In this article an advanced two-disc machine with sophisticated control technology for dry and lubricated setup is presented. (i) All involved components are controlled via a powerful PLC unit leading to the possibility of realising extremely accurate SRRs down to $0.1 \%$. (ii) High-speed data acquisition allows local insight into tribological phenomena by providing 72 data points along one shaft rotation. (iii) Several lubrication scenarios such as fluid, mixed, and starved lubrication, as well as dry contacts, can be considered. (iv) Raw-data of all sensors, including normal force, friction force, vibration speed, stiffness (wear), infrared temperature, contact potential, and motor speed, is presented. Some example results of dry polymer-steel tribosystems and lubricated experiments are shown to elucidate the capabilities of the novel test rig.
\end{abstract}

\section{Introduction}

The history of two-disc model testing goes back to 1935, when [1] introduced an apparatus for a simplified testing of worm gears. Ever since then this type of machines has become more popular among researchers, due to easy usage and comparability of test results to actual machine components. The simple cylindrical geometry enables a precise measurement of the friction force in the contact. Also, operating conditions, such as rolling velocity, slide-to-roll ratio, or contact pressure, in terms of normal force, can be adjusted easily. Furthermore, the machining of discs is more effective from an economic point of view in contrast to the complicated manufacturing process of gears. The tribological behaviour of machine elements, as for instance gears, is depending on operating conditions, lubrication (especially viscosity and additives of the oil), and surface structure [2]. The latter two factors can be depicted equivalently with a two-disc machine; however gears generally operate under transient conditions, due to the continuously changing normal force, sliding velocity, and contact radii, along the line of action [3]. A two-disc experiment typically depicts the operating states of a gear contact which are of greatest interest stationarily.
On the one hand such tests are carried out for a specific servicing point to determine the rolling contact fatigue (RCF) of certain tribological systems. Lifetime results of discs can be transferred to actual gears under certain conditions, as, for instance, explained in [4] or [5]. However, one has to keep in mind that transient phenomena seen in gears are impossible to reproduce with discs. Due to the high contact stresses, of at least $3 \mathrm{GPa}$, required for RCF testing, test-rigs are typically big and have to operate under severe loads, which requires high maintenance efforts and makes an accurate measurement of friction forces not feasible.

On the other hand, two-disc machines are employed for friction measurements of tribological contacts. It has been shown on numerous occasions $[6,7]$ that two-disc experiments can indicate how different aspects, such as fluid, surface finishing, surface texturing, or coatings, will affect the friction in gear systems.

With time machines have become more sophisticated, especially the advent of modern control technology opened the way to new testing concepts. While the older test-rigs were restricted to certain slide-to-roll ratios (SRR), typically determined by disc diameter or mechanical gear ratios, the 


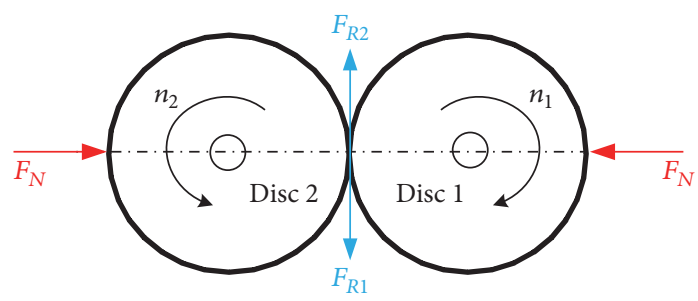

FIGURE 1: Basic principle of a two-disc machine.

usage of electrical drives allows a more precise setting of arbitrary SRRs. Nowadays numerous research facilities have engineered two-disc machines [8-12], which basically differ in type of frictional force measurement.

In contrast to other machines the presented test rig integrates several components in a programmable logic controller (PLC). This permits the evaluation and setting of parameters in real-time, enabling, for instance, a control loop between both motors leading to extremely accurate SRRs down to $0.1 \%$. Furthermore, the option to perform fully automated tests and data evaluation procedures is implemented. Due to the high computational power of the PLC a high-speed data evaluation, allowing detailed insight into local phenomena of tribological systems, becomes feasible. Also, multiple sensors, for the analysis of vibrations, stiffness, wear, temperatures, and contact potential, are integrated in order to gain a profound understanding of the tested tribosystems. Raw-data of all sensors is presented, while other papers typically only publish postprocessed traction curves.

\section{Machine Setup}

The basic principle of a two-disc machine is depicted in Figure 1.

The discs are loaded with a normal force $F_{N}$ and rotating with speeds $n_{1}$ and $n_{2}$. When the speeds of the discs are not equal, a friction force vector, with equal norm but different direction, results on the surfaces of both discs. This force ultimately determines the frictional performance of the tribological system and is therefore the desired quantity to be measured. In the case of cylindrical specimens, the direction of the friction force vector is time independent, contrary to gears, where the friction vector is changing with time along the line of action, which makes it difficult to diagnose.

Several methods exist in order to measure the friction force in two-disc machines. One way is the usage of torque transducers, which are applied to a shaft on which the machine element of interest is mounted. Papers [11, 12] are, for example, employing this technique for friction force determination in their test-rigs. However, one has to consider that parasitic influences, such as losses of roller bearings of the shaft, or sealing losses, are measured as well by this setup. Depending on the type of roller bearings and sealings in the machine, it can therefore be very difficult to determine the actual friction force accurately in the contact. Another possibility is the usage of a force transducer, which is positioned in line to measure the friction directly, as, for

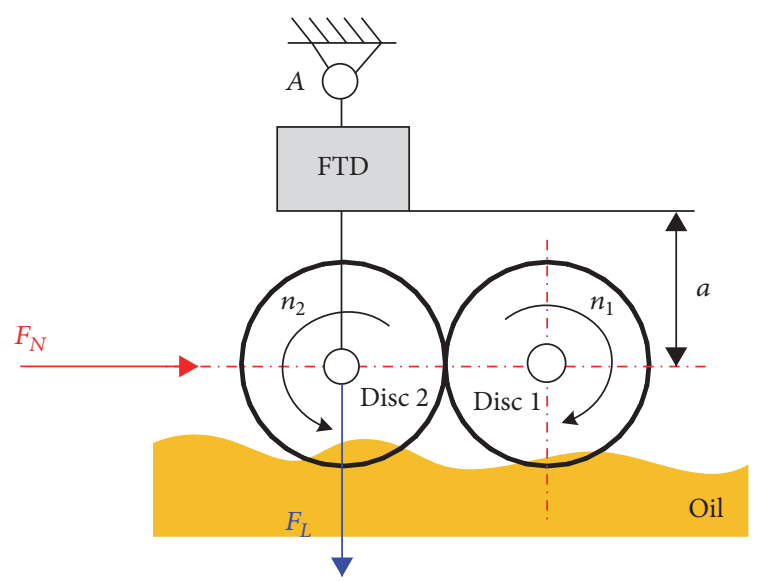

Figure 2: Measurement concept of the presented two-disc test rig.

instance, described in [9]. This way, the measurement of parasitic forces can basically be avoided.

The direct friction force measurement principle via force transducer is employed in the presented test rig, which is based on previous developments at the Chair of Mechanical Engineering, Montanuniversität Leoben $[13,14]$, as illustrated in Figure 2.

The shaft of disc 2 is mounted in a housing, which can rotate with respect to point $A$; therefore any friction force appearing on disc 2 is directed to the force transducer via shaft, bearings, and housing. The force measured is denoted as $F_{L}$, whereby it has to be taken into account that the weight force of the housing and its components is measured as well. This force is quantified by a highly precise force transducer, in our case a uniaxial, laterally compensated force transducer of type $H B M U 10 M$.

Figure 3 displays a cut through the fluid chamber, of the computer-aided-design (CAD) assembly, and a photograph of the actual test rig, which has been taken during an experiment with grease lubrication. Note that the view of the photograph is rotated ninety degrees clockwise with respect to the CAD image.

The disc specimens, which have a diameter of $50 \mathrm{~mm}$, are mounted onto the respective shaft with a spring key and fixed axially by a screw. The normal force is induced into the system by a Norgren pneumatic cylinder via the rear of the housing, which also mounts shaft 1 . On the left of Figure 3 the initiation of the normal force is illustrated by the vector $F_{N}$. The mechanism for the application of the normal force is presented in Figure 4. To make sure that the desired amount of force is applied, a force transducer is placed directly in the loading path next to the cylinder. A roller is used to transfer the load into the system in order to eliminate disturbances which can affect the friction measurement.

Flywheels can be mounted on the shafts optionally to increase the moment of inertia of the system in order to prevent motor control issues when high friction forces spontaneously (e.g., seizure) occur in the contact. For the results presented in this article no flywheels are used. Each shaft is connected to a motor by employing a coupling. 


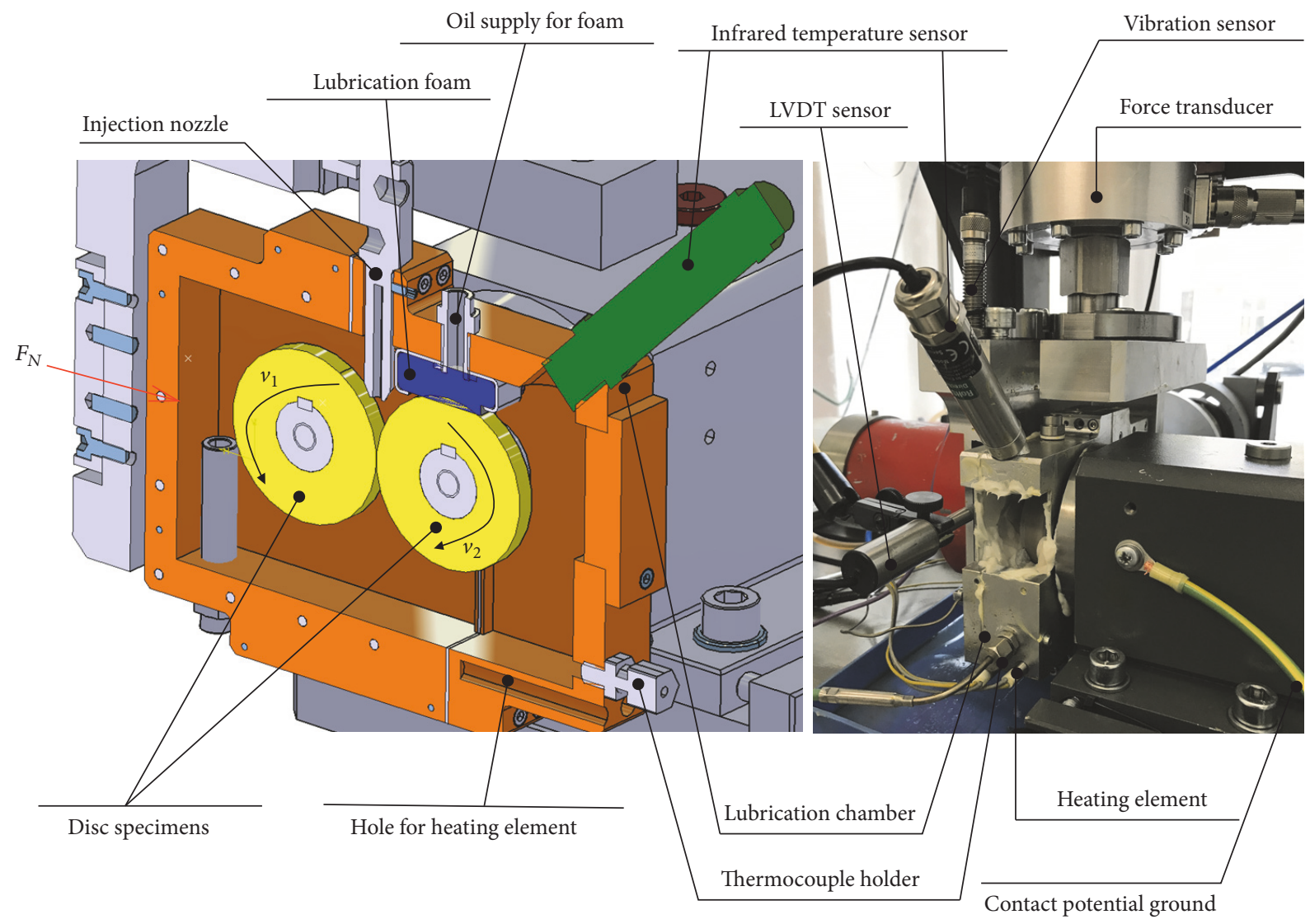

(a)

(b)

Figure 3: Cut through the lubrication chamber (a) and photograph of the machine (b).

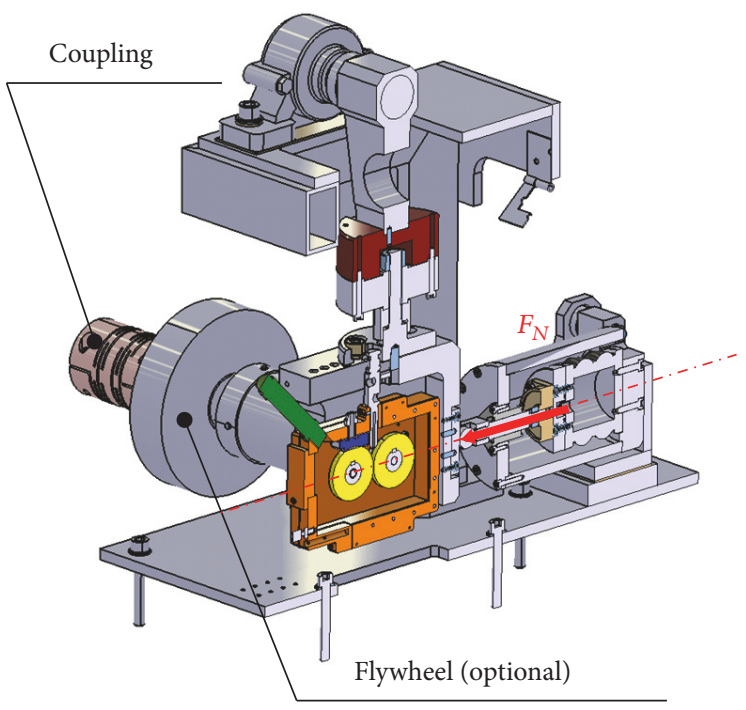

(a)

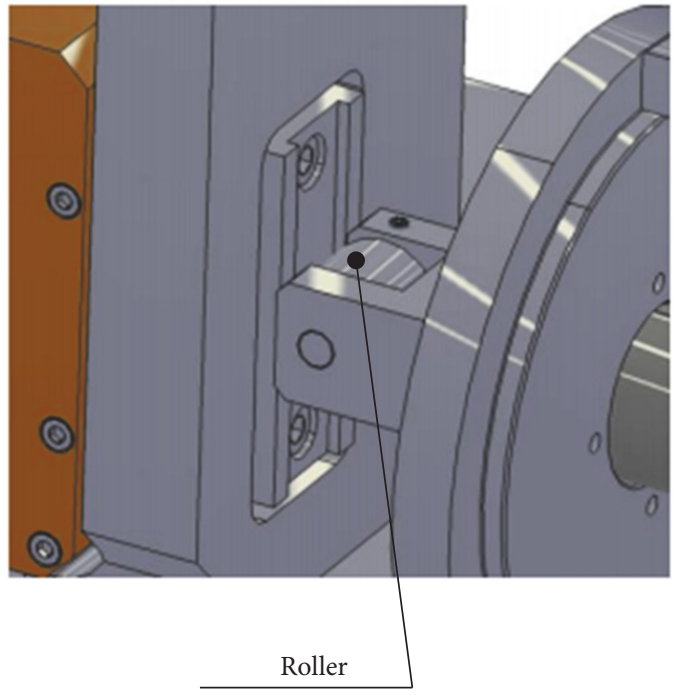

(b)

Figure 4: Application of the normal force by a pneumatic cylinder. Rear view (a) and force application via a roller (b). 


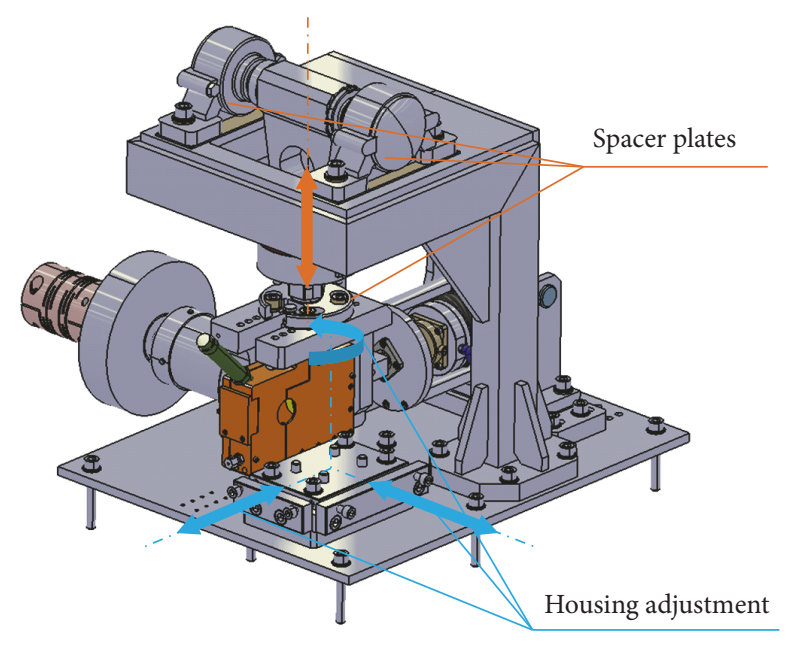

FIGURE 5: Options for contact alignment.

In order to adjust the alignment of the disc specimens, which is paramount for performing high quality measurements, several options are available, which are highlighted in Figure 5.

The horizontal position of the housing, which mounts shaft 2 , can be adjusted via screws and the vertical position of shaft 1 is precisely set by utilising spacer plates with a thickness of $0.1 \mathrm{~mm}$. The alignment is considered successful when an application of the normal force is not altering the friction force $( \pm 1 N)$, whereby the motors are switched off. Furthermore, a pressure foil (Fujifilm), which locally determines the pressure by colouring, is utilised in order to guarantee an optimal contact pattern.

A piezoelectric vibration sensor is integrated into the machine for the detection of wear phenomena or specimen with intolerable eccentricity.

Several lubrication scenarios, from dry to fully flooded conditions, can be realised with this test rig. In the case of splash lubrication, the chamber is filled with a volume of about $250 \mathrm{ml}$ fluid. This ensures that both discs are dipped $11 \mathrm{~mm}$ into the fluid. There is a small gap between the lubrication chamber and the shaft of disc 2, which can cause minor leakage when the machine is operating under high speed. However, additional fluid can be provided via the injection nozzle in this case. The primary field of use for the injection nozzle is the analysis of starved lubrication systems; therefore a LECHLER pneumatic nebuliser is installed in the test machine. The amount of injected fluid is controlled by a FESTO LR DB pneumatic control unit, which permits a fine dosage of fluid air mixture to be injected directly into the contact line of the discs. To investigate even severe starved lubrication conditions, a foam holder, which is pressing an oil soaked foam unit onto disc 2 , is available as well.

Another important issue is the control of the lubrication chamber temperature. Hence, the machine is equipped with four heating elements with a power of $150 \mathrm{~W}$ each, which are mounted directly in the aluminium lubrication chamber for optimal heat transfer to the fluid. The agile control loop can

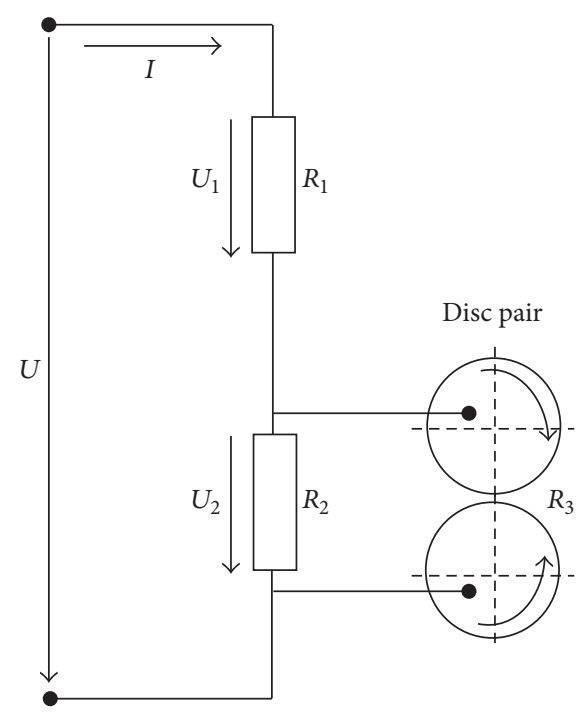

FIGURE 6: Electrical circuit for contact potential measurement.

TABLE 1: Set variables for the two-disc machine.

\begin{tabular}{lc}
\hline Name (abbreviation) & Value range \\
\hline Slide-to-roll ratio $(s, \mathrm{SRR})$ & $0-200 \%$ \\
Normal force $\left(F_{N}\right)$ & $100-2000 \mathrm{~N}$ \\
Speed $\left(n_{1}, n_{2}\right)$ & $0-4500 \mathrm{rpm}$ \\
Temperature $\left(T_{0}\right)$ & $\mathrm{RT}-150^{\circ} \mathrm{C}$ \\
Fluid injection $\left(\dot{V}_{\text {in }}\right)$ & $20 \mathrm{ml} / \mathrm{min}-300 \mathrm{ml} / \mathrm{min}$ \\
\hline
\end{tabular}

heat the lubricant from room temperature to about $65^{\circ} \mathrm{C}$ in only forty seconds.

A linear variable differential transformer (LVDT) sensor is integrated into the machine for stiffness and wear measurements. This transducer can resolve length scales in range of microns and is therefore suitable for wear investigations. This sensor is positioned on the housing, which can rotate with respect to point $A$, as illustrated in Figure 2. Therefore, any wear or changes of stiffness, which can for instance occur temperature dependently, are directly translated into the housing and measured via the displacement sensor.

Three different temperature sensors are mounted around the chamber and a thermocouple holder is fixed in the chamber directly, allowing for Type-K thermoelements to measure the temperature of the oil.

Furthermore, an infrared sensor is measuring the temperature on the surface of disc 2 at an angle of $135^{\circ}$ next to the contact line.

Housing and shaft of disc 1 are electrically isolated with respect to disc 2 which allows a contact resistance measurement of the tribological system and therefore binary judgement of the state of friction. A sketch explaining the contact potential measurement system is provided in Figure 6.

All set variables, as well as measured properties, are depicted in Tables 1 and 2, respectively. 


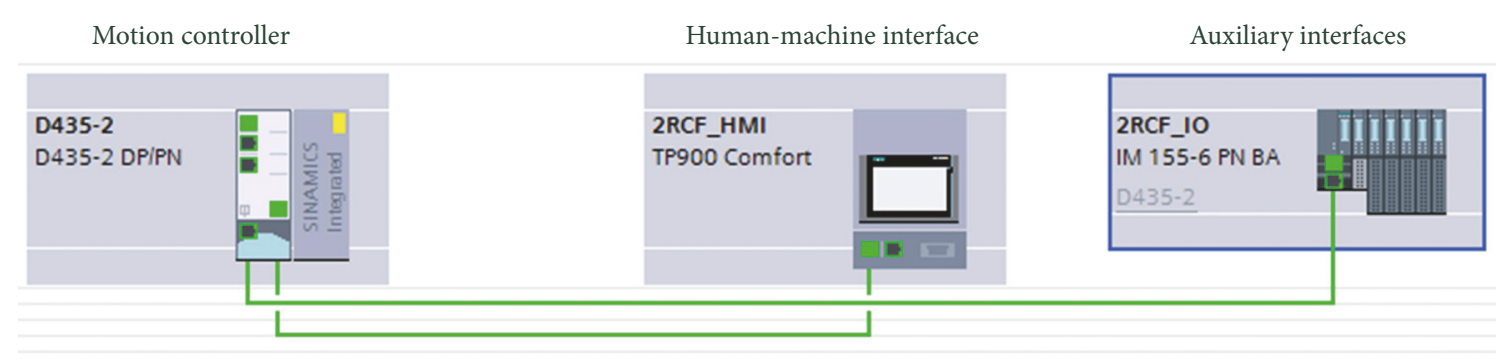

FIGURE 7: Sketch of the major electrical components.

TABLE 2: Measured variables.

\begin{tabular}{lc}
\hline Name (abbreviation) & Value range \\
\hline Friction force $\left(F_{R}\right)$ & $0-1000 \mathrm{~N}$ \\
Infrared temperature $\left(T_{I}\right)$ & $0-160^{\circ} \mathrm{C}$ \\
Oil-bath temperature $\left(T_{O}\right)$ & $0-200^{\circ} \mathrm{C}$ \\
Lubrication chamber temperature $\left(T_{C}\right)$ & $0-200^{\circ} \mathrm{C}$ \\
Contact potential $\left(c_{\text {pot }}\right)$ & $1-100 \mathrm{mV}$ \\
LVDT distance $\left(s_{\mathrm{LVDT}}\right)$ & $1 \mu \mathrm{m}-2 \mathrm{~mm}$ \\
Vibration sensor $\left(v_{\mathrm{vbs}}\right)$ & $0-10 \mathrm{~mm} / \mathrm{s}$ \\
\hline
\end{tabular}

The highest possible Hertzian pressure is depending on the actual width of the discs. For the case of a disc thickness of $5 \mathrm{~mm}$ the contact pressure limit is $1.1 \mathrm{GPa}$. The corresponding velocity for a specimen diameter of $50 \mathrm{~mm}$ is in the range of $0-11 \mathrm{~m} / \mathrm{s}$.

2.1. Electrical Architecture. Figure 7 illustrates schematically the involved major electrical units of the presented twodisc machine. The system is operated by a Siemens D435-2 digital control unit which permits real-time cycles of up to $1000 \mathrm{~Hz}$. The controller not only acts as real-time controller for both drives, but also features motion chart controls for the sequential main flow as well as transient data logging and several force and temperature closed loop controls. The tribological test rig demands several analogue and digital inand outputs for actuation and measurement. This peripheral IO is implemented as Siemens ET200SP station. In addition, the force signal is transmitted by a HBM digiclip device, which is connected to the main controller via Profibus. Finally, the digital control unit Siemens D435-2 embeds also the motion controller axis featuring SINAMICS Integrated technology.

The human-machine-interface is realised as a Siemens TP900 touch panel [15], which is connected via Profibus to the digital control unit. This panel is used for machine monitoring, specification of set values, and low speed data acquisition. Furthermore, fully automated tests can be performed via the recipe system [16]. In addition, the touch panel acts as VNC-server within the local area network and simplifies therefore user operating and supervision issues. Figure 8 displays the human-machine-interface covering the definition of set values based on the recipe system. Furthermore, the recipe based test programme can be looped to extend the test time. The test run is switched off if a certain number of steps or a certain value of test time, temperature, vibration speed, friction force range, or displacement is exceeded. The human-machine-interface supports manual as well as automated test programmes. The first are used for initial studies; in case of unknown material or lubricant behaviour, the latter are applied to maintain identical test settings.

Besides the reproducible definition of set values and shutdown criteria, the monitoring of the actual values and their data logging is important for scientific evaluations of the tribological system. The speed of the drive axis, slip, friction force, contact potential and displacement sensor values are of interest for the user. The measured data is displayed in Figure 9 based on a cyclic refresh rate of about five hundred milliseconds. Aside this quasi-stationary evaluation, a high-speed transient data logging, featuring one thousand measurement points per second, is also implemented in the digital control unit.

The Sinamics S120 double motor module [17] is powering both Siemens 1FT7 PESM machines [18], with a nominal power of $3.77 \mathrm{~kW}$ each. The synchronous motor has an integrated high-resolution incremental encoder which is connected via the DRIVE CLiQ technology to the motor module. This hardware design facilitates, in combination with the Simotion control technology, a highly accurate adjustment of SRRs down to $0.1 \%$. A stable velocity control is especially demanding at low speed set points, since the local variations in friction forces may disturb the speed controlled axis. Hence, the speed control of the underlying SINAMICS Integrated drive technology is set up to handle such disturbance moments quickly and stably. The closed loop control of the drive unit is initially parametrised by automatic control routines available in SIEMENS Scout/TIA Portal. In addition, the bearing dependent friction losses for each axis are also compensated by this drive technology.

All previously mentioned auxiliary components, such as analogue and digital in- and outputs, amplifier units for force measurement, pneumatic control valves, temperature sensors, fuses and connector devices, are assembled in an electrical cabinet close to the two-disc test rig. The touch panel is also integrated in the cabinet to support an easy onsite user-operation.

2.2. Control Setup. For the configuration and programming, of both drive and control related functionalities, SIEMENS Scout/TIA Portal is used [16]. As mentioned before, the speed drives are based on a SINAMICS Integrated technology which 
SIEMENS

SIMATIC HMI

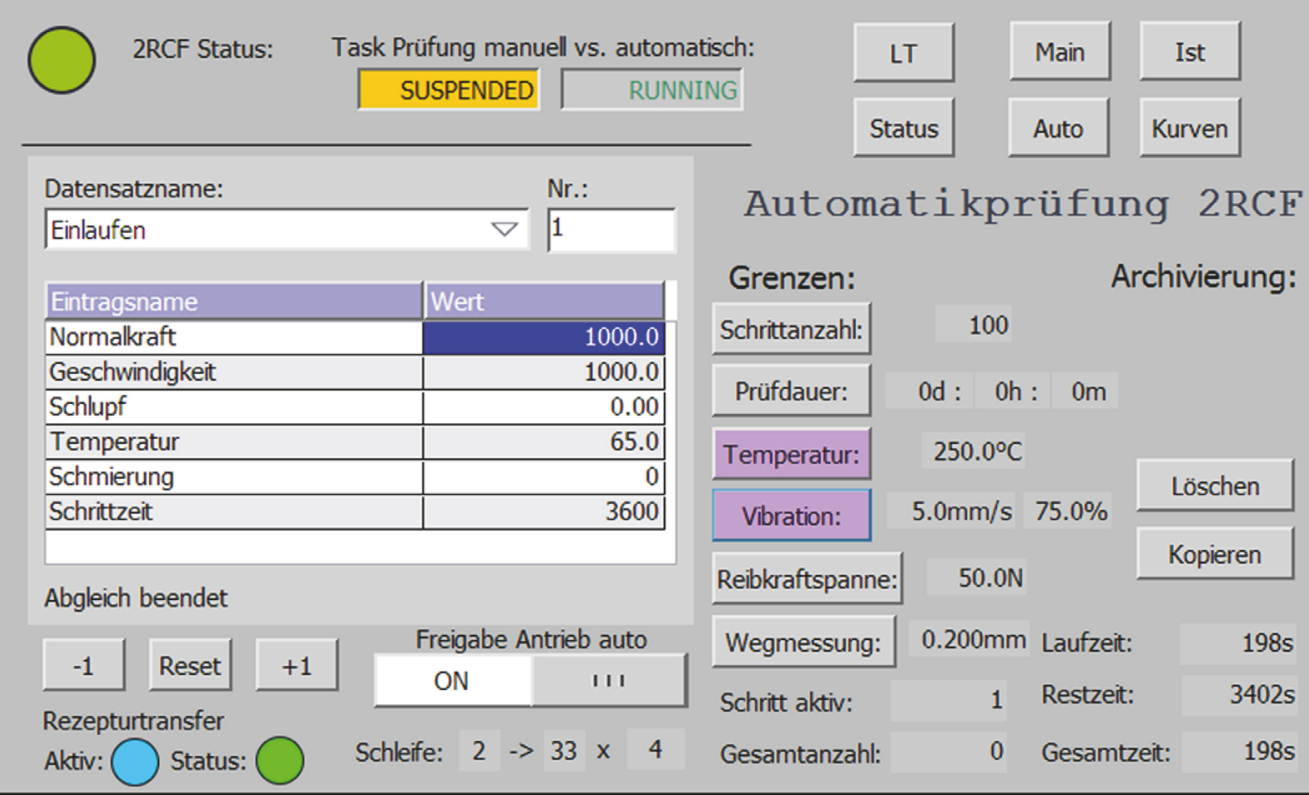

FIgURE 8: Recipe based set value interface including test limits settings.

\section{SIEMENS}

SIMATIC HMI

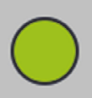

2RCF Status:

\section{Task Prüfung manuell vs. automatisch:

$$
\text { SUSPENDED } \longdiv { \text { RUNNING } }
$$

Istwerte 2RCF

Reibkraft Brutto:

Reibkraft Netto:

Reibkraft Peak-to-Peak:

Normalkraft:

Aktualdruck Regelventil:

Weggeber:

Potentialmessung:

Vibrationsmessung:

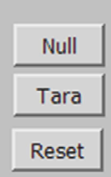

$19.9 \mathrm{~N}$

$1000.6 \mathrm{~N}$

3.67bar

Temperatur Tauchbad: $\quad 24.40{ }^{\circ} \mathrm{C}$

Temperatur Infrarot:

$26.69^{\circ} \mathrm{C}$

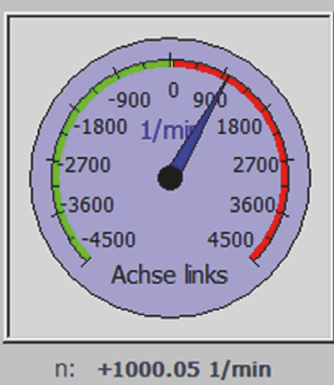

$\mathrm{M}$

Reibwert:

Schlupf

$22.0^{\circ} \mathrm{C}$

$-0.1 \%$

$0.00 \%$
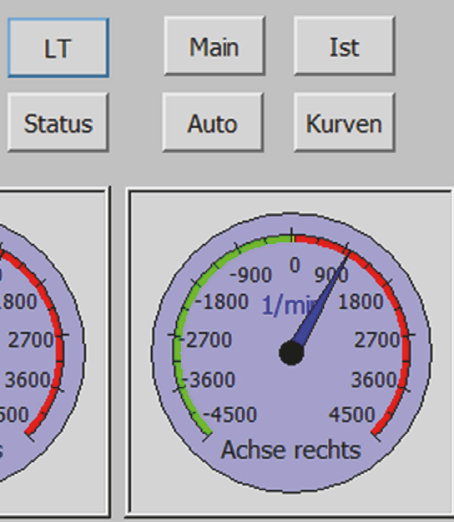

$\mathrm{n}:+1000.111 / \mathrm{min}$

M:

$+1.59 \mathrm{Nm}$

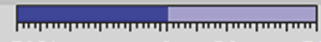

$\begin{array}{llll}-50 \% & 0 & 20 & 50 \%\end{array}$

$\begin{array}{lll}-100 \% & 0 & 0 \\ 100 \%\end{array}$

Aktueller Schritt:

Figure 9: Actual value human-machine-interface. 


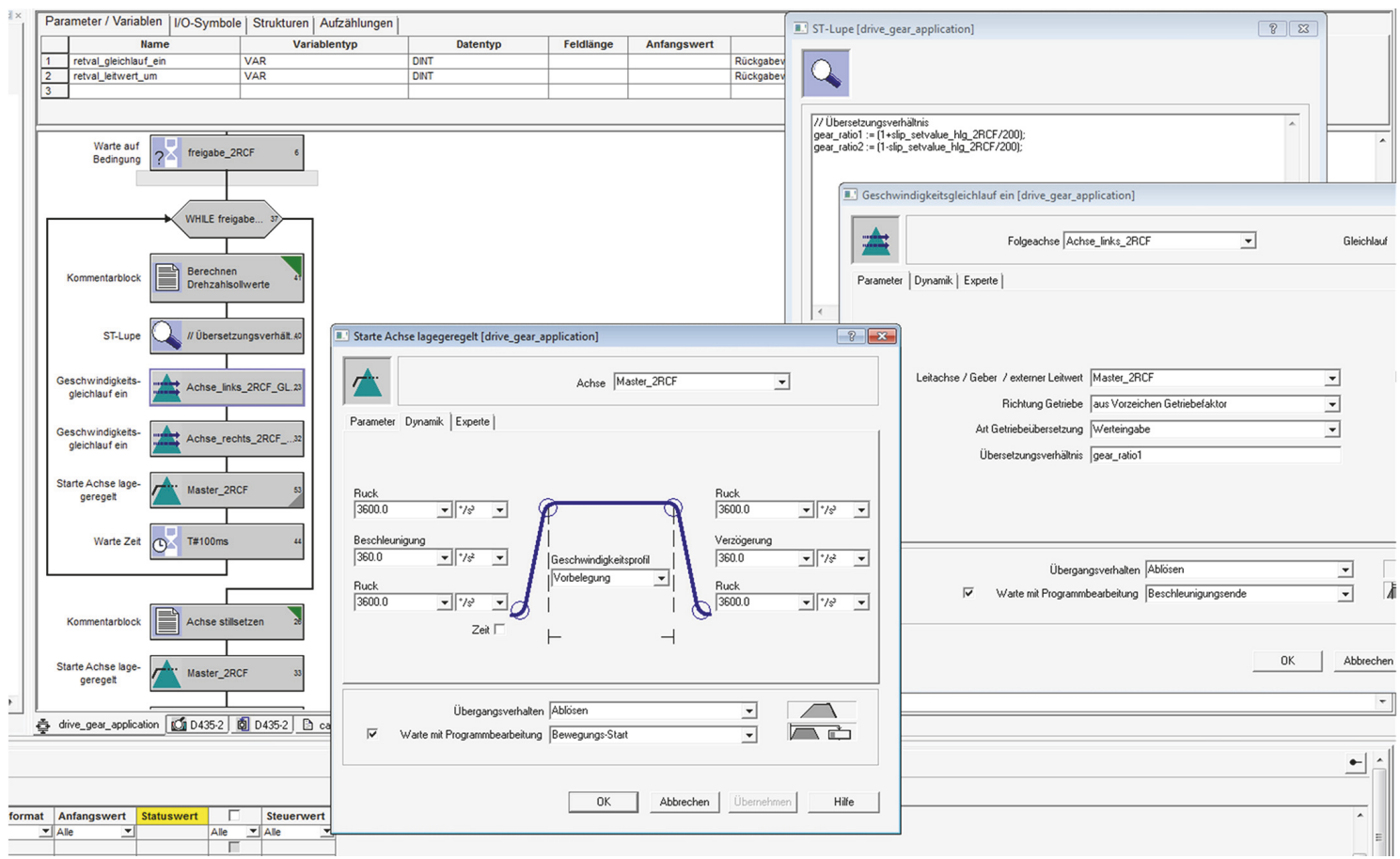

FIGURE 10: Motion control chart enabling speed synchronisation for varying slip set values by virtual master axis and incorporated gear transmission for each drive axis.

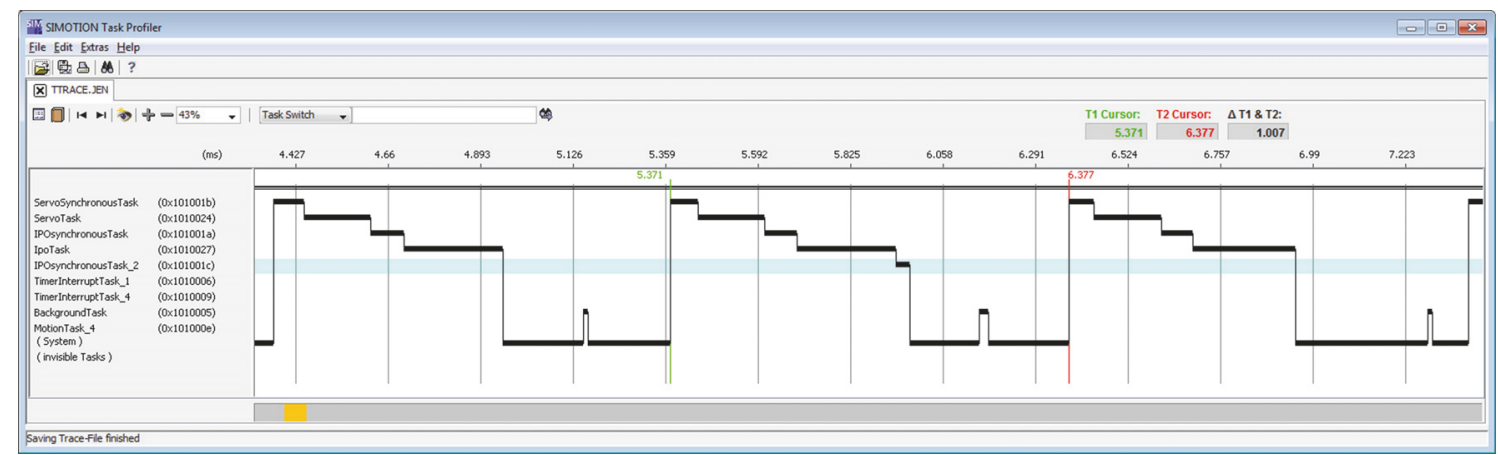

FIGURE 11: Task profiler of D435-2 real-time control system of two-disc tester.

utilises an internal control clock frequency of eight thousand Hertz. The position control of the D435-2 defines the motion of both axes by implementation of a virtual master axis. A common synchronism is guaranteed as the speed of this virtual master axis is modified by the given slip set value for each drive axis. The implemented programme section is shown in Figure 10. The speed set value for each axis is generated by the interpolator clock. To ensure a high dynamic response of the system, the interpolator clock is set equal to the servo clock pulse of one millisecond. To fasten the servo control further, the option Dynamic Servo Control is activated, which causes the superimposed position controller to be run in the clock pulse of the Simotion speed control unit. The speed set value is interpolated based on the data obtained from the virtual master axis. This guarantees a high bandwidth for the drive control of both test rig axes.
The real-time drive control system utilises therefore the servo task, the interpolator synchronous task, and finally the interpolator task with an identical clock pulse of one millisecond. The control programme is split up into motion tasks, which are processed on the basis of a certain motion requirement or started by other tasks; servo-synchronous tasks for the conversion of IO-devices related data: cyclic high-speed logging and evaluation of transient changes, for example, in angular position and friction force values, is taken into account by interpolator synchronous processing; timerbased interrupt tasks with decreased sample rates facilitate real-time processing of closed force or temperature control loops and logging issues; and finally, the background task handles the start and stop procedure of the overall test rig. Figure 11 exhibits the task profile of the D435-2 control unit. 


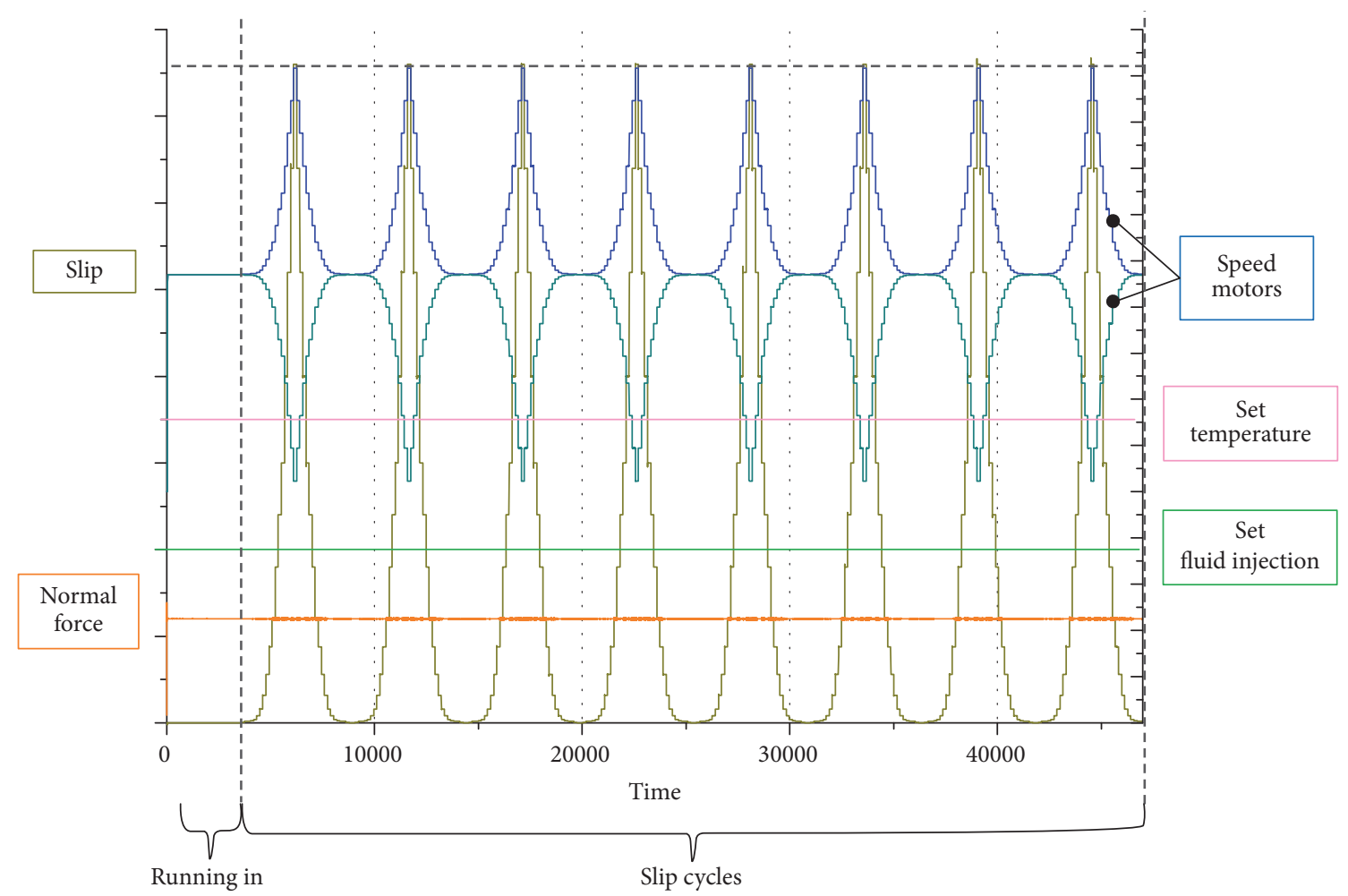

FIGURE 12: Test programme for presented experiments.

Utmost priority has the servo task, which handles the position control of each axis. The corresponding speed set value is continuously derived in interpolator task. The interpolator task covers several time-critical user-defined processes; hence it necessitates already about one-quarter of the overall available clock pulse for itself. Motion tasks are carried out on demand; the background task is processed dependent on the free time slot between each cycle. As transient data logging is implemented in the fast interpolator task, it is possible to gather transient values of friction force, vibration velocity, and others within a $4 \mathrm{k}$-buffer. These buffer values are then periodically evaluated and mapped onto a result matrix covering steps of five degree angles. This realtime based, transient data evaluation enables an improved high-speed data measurement and gains additional insight into local changes of the tribological system.

\section{Experimental Results and Discussion}

In this section exemplary results are presented to emphasise functionalities of the developed two-disc machine.

3.1. Test Programme. The term test programme is used for the description of all available set values as a function of time. For the experiments presented in this article, a cyclic slip programme with running-in phase, as illustrated in Figure 12, is applied.

Firstly, typically one hour is spent for a running-in procedure of the system and also in order to reach a thermally stable state of the machine. Then, slip and therefore motor speed are increased (or decreased in case of the other axis) stepwise until the maximum slip is reached. After the maximum slip is maintained, an incremental decrease of the slip is performed in order to return to the initial state. Those slip cycles are repeated throughout the experiment, whereby total time for the test is typically in the range of four to twelve hours, depending on the number of slip cycles actually performed. The set parameters, including temperature, fluid injection rate, and normal force, are kept constant throughout the tests presented in this paper. The slide-to-roll ratio is defined according to

$$
\mathrm{SRR}=s=\frac{u_{1}-u_{2}}{u_{m}}
$$

whereby the mean velocity is kept constant throughout each test:

$$
u_{m}=\frac{u_{1}+u_{2}}{2}
$$

3.2. Lubricated Steel-Steel Experiment. In this subsection experiments that are carried out with discs made of hardened $42 \mathrm{CrMo} 4$ and super-finished surface, with a roughness of $R_{a} 0.03 \mu \mathrm{m}$, using a mineral oil under splash lubrication, are presented. The thickness of one disc has been reduced from $11 \mathrm{~mm}$ to $5 \mathrm{~mm}$ to improve contact alignment and enable the testing of increased contact pressures. The respective operating and material parameters are given in Table 3. 


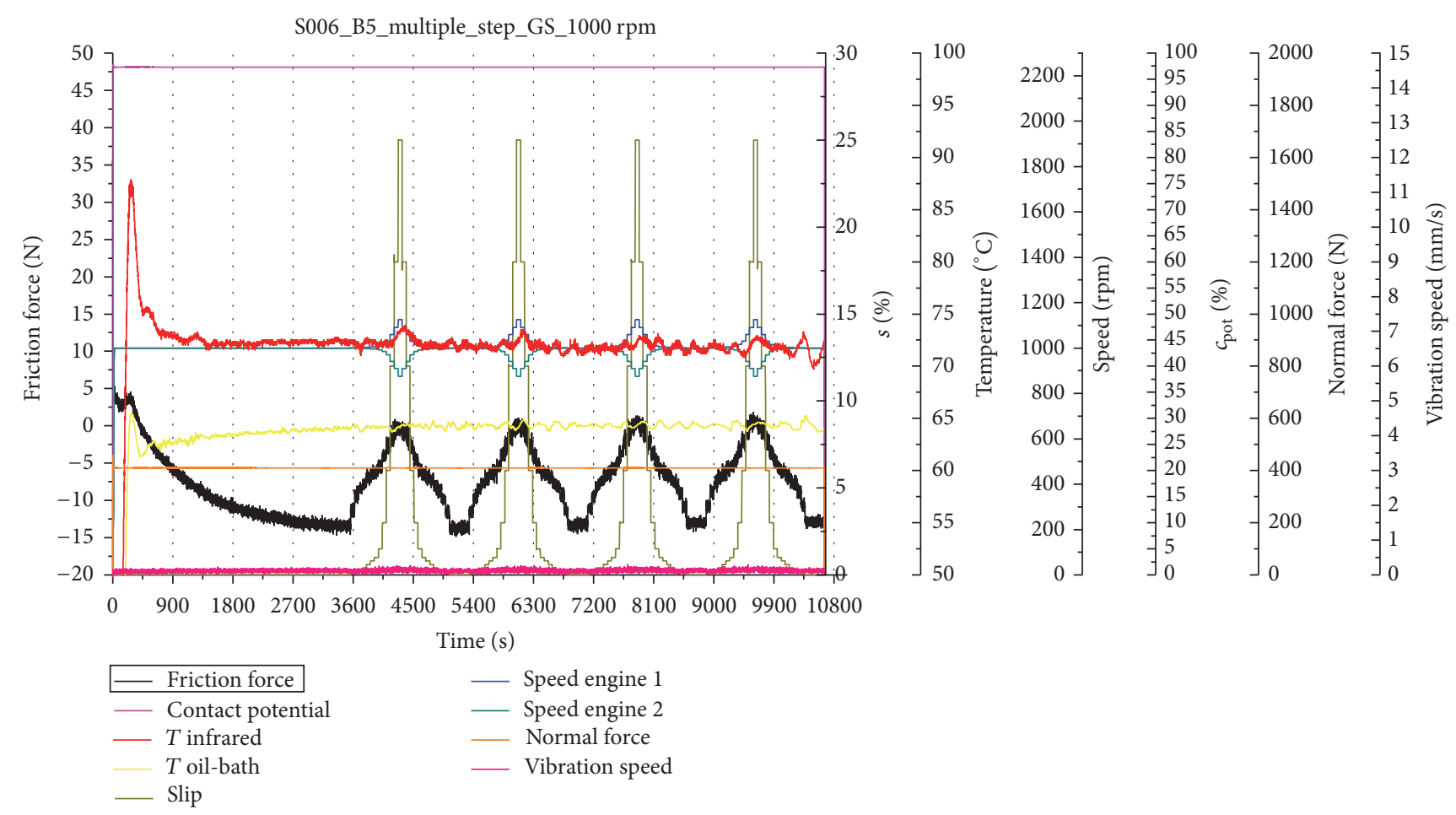

FIGURE 13: Results for a steel-steel experiment under splash lubrication.

TABLE 3: Operating and material parameters for lubricated steelsteel experiment.

\begin{tabular}{lc}
\hline$u_{m}=2.6 \mathrm{~m} / \mathrm{s}$ & $s=0-25 \%$ \\
$r_{1}=25 \mathrm{~mm}$ & $r_{2}=25 \mathrm{~mm}$ \\
$E_{1}=210 \mathrm{GPa}$ & $E_{2}=210 \mathrm{GPa}$ \\
$\nu_{1}=0.3$ & $\nu_{2}=0.3$ \\
$b_{1}=5 \mathrm{~mm}$ & $b_{2}=11 \mathrm{~mm}$ \\
$R_{a}=0.03 \mu \mathrm{m}$ & $\eta\left(T=40^{\circ} \mathrm{C}\right)=95.52 \mathrm{~mm}^{2} / \mathrm{s}$ \\
$T_{0}=64^{\circ} \mathrm{C}$ & $p_{\max }=0.5 \mathrm{GPa}$ \\
\hline
\end{tabular}

A graph of selected measured variables, depending on time, is shown in Figure 13. The test programme is started with a running-in phase, which lasts for one hour, followed by four slip increase-decrease cycles. It takes about 2,700 s for the temperature control loop to reach a steady state, during this time the whole machine, including the electric motors, is experiencing temperature changes, which lead to an elongation of components and therefore a continuous change of the measured friction force during this phase. However, afterwards a steady state of the measured friction force is reached, which indicates a thermally stable system.

During each cycle, the slip is increased stepwise to its maximum value and then decreased to zero again. The friction force is, at very low slip values, increasing linearly; however shear-thinning and thermal effects cause nonlinear effects at high slip rates [19]. The oil-bath temperature is constantly in the range of $64^{\circ} \mathrm{C}$ throughout the experiment; however the infrared temperature, which is actually measuring the fluid film on disc 2 , is experiencing more pronounced changes, especially when slip is high. With increasing slip the frictional power of the system is raised; consequently higher temperatures can be expected. Small fluctuations, which occur independently of slip, are caused by the heating control loop. Also note that the contact potential is holding its maximum value throughout the experiment, indicating a continuous operation in the fluid friction regime.

The friction force measurements from Figure 13 are then postprocessed to derive traction curves, which show the coefficient of friction (COF) as a function of slip, as illustrated in Figure 14. Average values for each slip-step are calculated in order to generate these graphs. The vertical bars indicate the standard deviation occurring along one slip-step.

The excellent reproducibility of the traction curves indicates stable machine conditions and the absence of wear in the tribological system, which is also confirmed by the very low vibration speed values seen in Figure 13. The behaviour of the fluid is therefore Newtonian below a slip rate of $0.5 \%$; thereafter thermal effects and viscosity dependence on shear rate significantly reduce the slope of the traction curve [19].

3.3. Validation. In this part of the article the influences of pressure, speed, and oil-bath temperature on traction curves are investigated and compared to state-of-the-art results as, for instance, presented in [6]. Assuming that all tests are operated under fluid lubrication, the following main findings have been concluded in [6].

(i) Finding 1. With increasing pressure the COF is shifting towards higher values for all slip values. This is due to the increasing viscosity at elevated pressure and the 


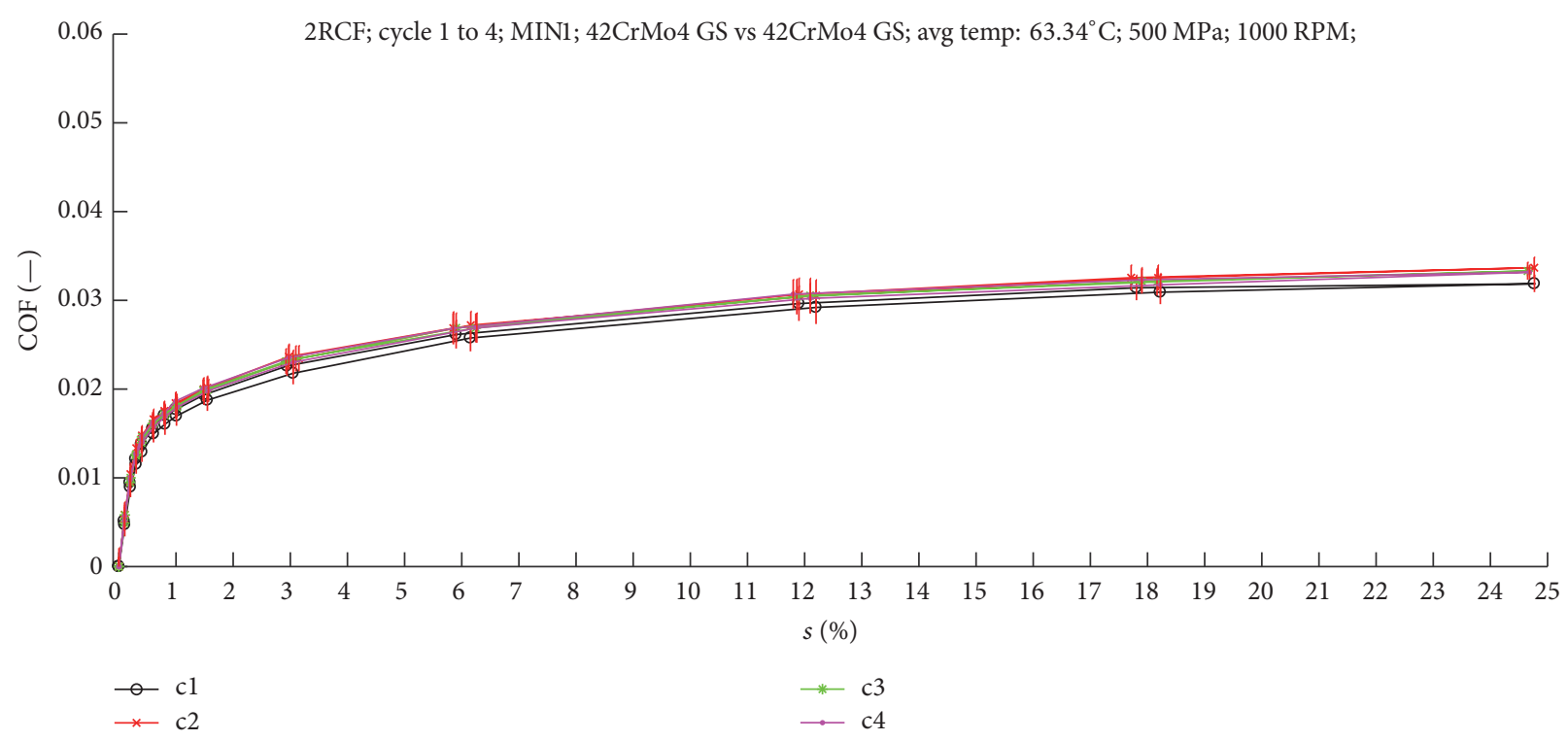

FiguRE 14: Traction curve for a steel-steel experiment under splash lubrication.

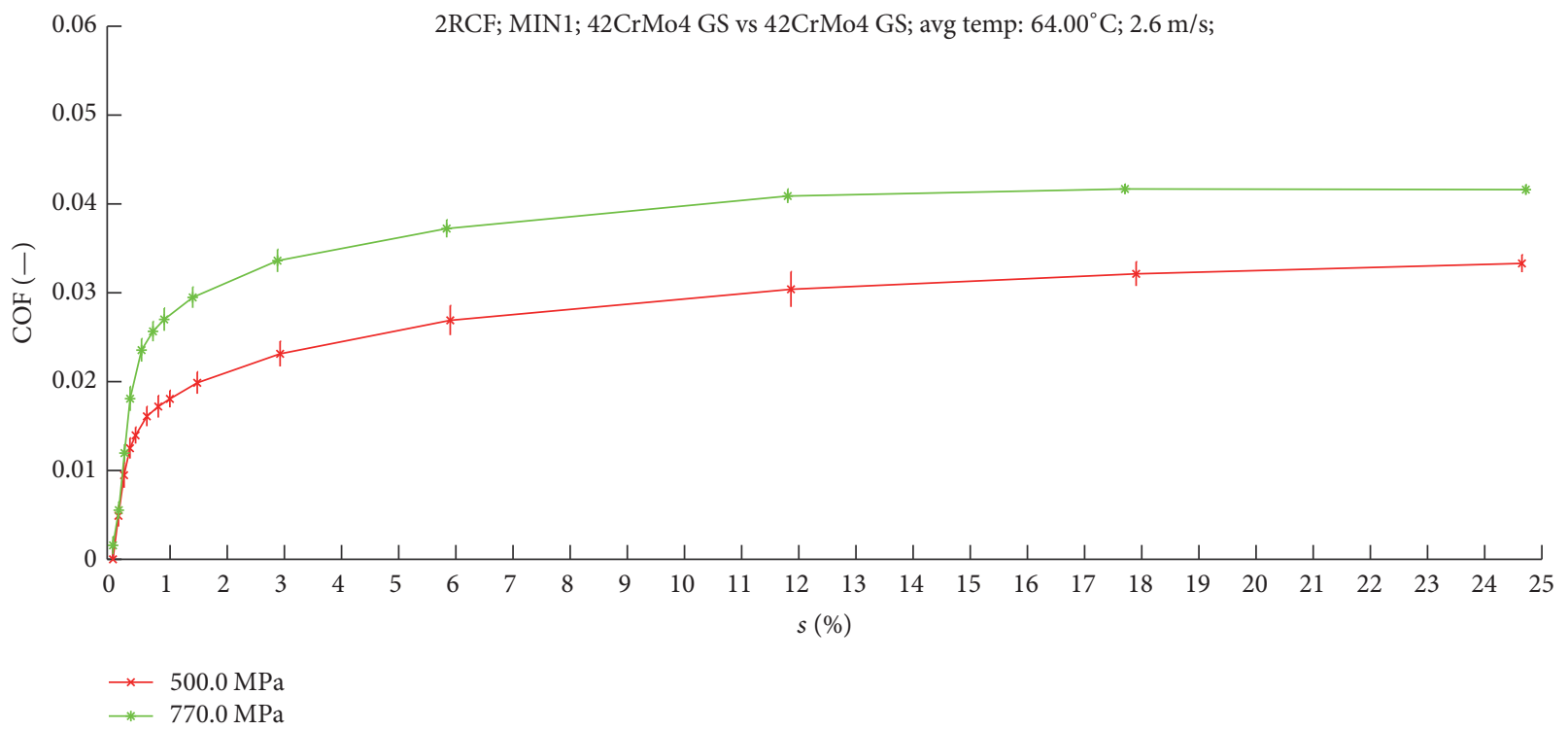

FIGURE 15: Influence of pressure on traction.

limiting shear stress of lubricants is known to linearly rise with pressure, which has been shown in [20].

(ii) Finding 2. A higher velocity $\left(u_{m}\right)$ is linearly raising the frictional power at constant slip (SRR $>0)$. The film thickness is increasing as well when the entrainment speed is raised. Experiments have shown that a higher speed leads to a lower COF. This effect is growing with slip since the frictional power increases with slip.

(iii) Finding 3. The oil-bath temperature is a highly influential parameter since it strongly affects the lubricant's viscosity. Therefore an elevated temperature decreases the COF unless the mixed lubrication regime is reached.
Results of experiments, carried out with parameters as listed in Table 3, with exception of the currently investigated influence, are presented and compared with the findings made by other authors.

In comparison to Figure 14 only the rising traction curve of the third cycle of the respective experiment is illustrated in the graphs in order to improve readability.

3.3.1. Pressure Influence. Figure 15 investigates the influence of pressure on traction. Values of $500 \mathrm{MPa}$ and $770 \mathrm{MPa}$ are compared under otherwise same conditions.

Conclusions drawn in Finding 1 can be confirmed by this test. Also note that the $770 \mathrm{MPa}$ traction curve has a 


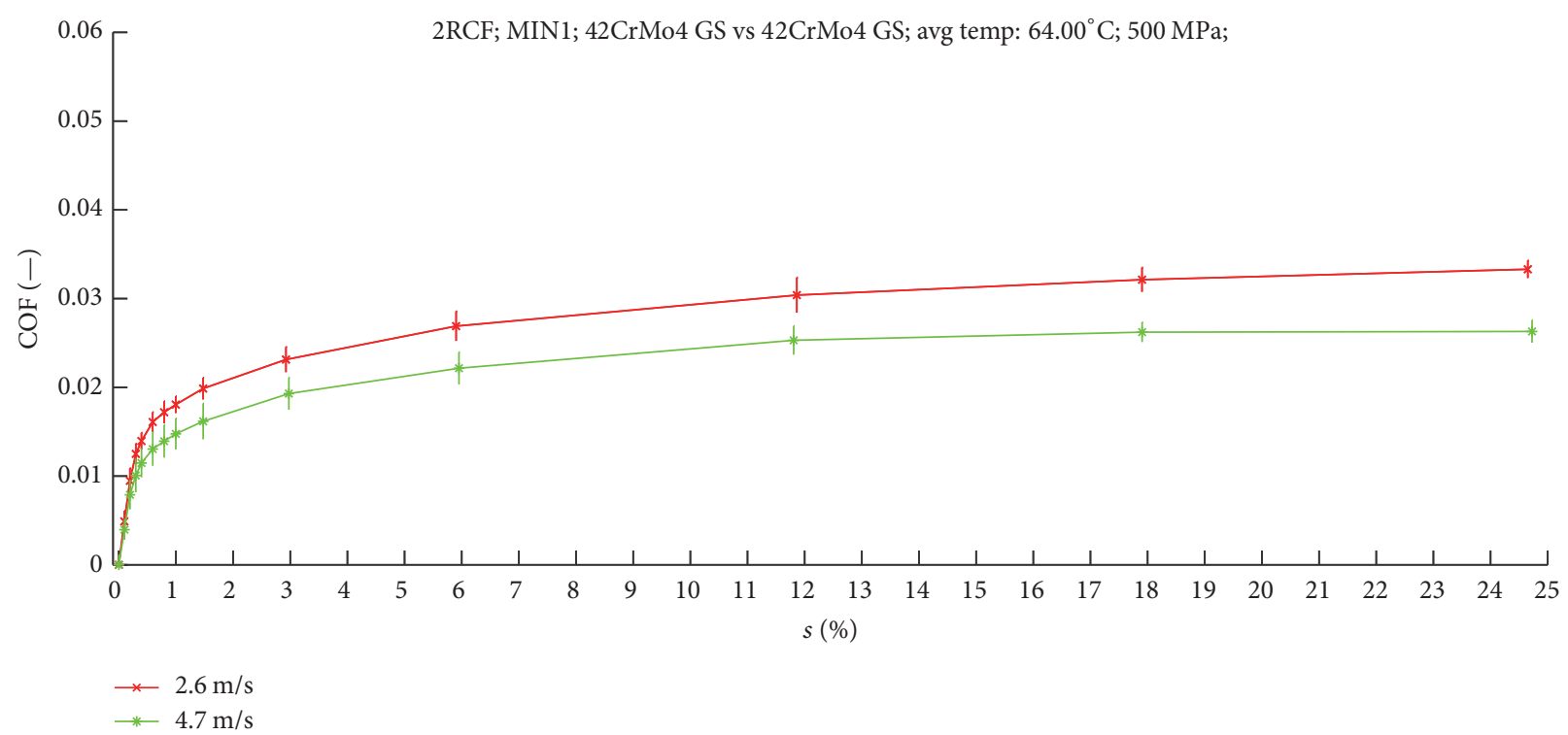

FIGURE 16: Influence of speed on traction.

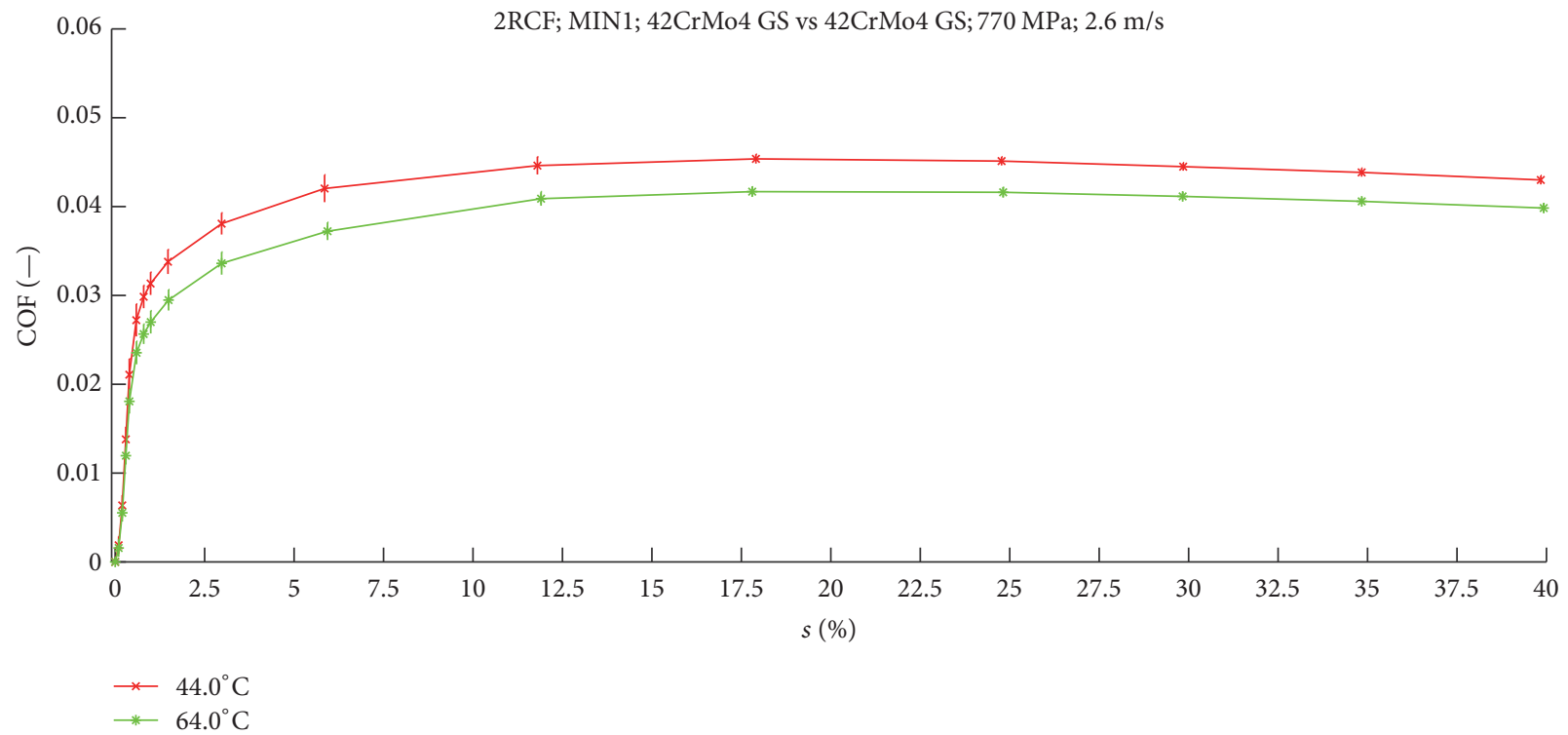

FIGURE 17: Influence of temperature on traction.

maximum at $\mathrm{SRR}=18 \%$ due to the increased viscosity, which leads to a higher frictional power, while the $500 \mathrm{MPa}$ curve is steadily increasing throughout the investigated slip range.

3.3.2. Speed Influence. Two different velocities $\left(u_{m}\right), 2.6 \mathrm{~m} / \mathrm{s}$ and $4.7 \mathrm{~m} / \mathrm{s}$, are examined in Figure 16.

The curve representing a speed of $4.7 \mathrm{~m} / \mathrm{s}$ yields a lower COF, whereby this effect is more pronounced at higher SRRs. This is corresponding well to Finding 2.

3.3.3. Temperature Influence. Finally, experiments with two different oil-bath temperatures are compared in Figure 17.
Note that these experiments are carried out with a Hertzian pressure of $0.77 \mathrm{GPa}$ and an increased slip range up to SRR = $40 \%$, in order to raise the frictional power of the system.

One can note that in both cases a COF maximum is reached, indicating a transition into the thermal area, where the COF is lowered predominantly by thermal effects. As expected an oil-bath temperature of $44^{\circ} \mathrm{C}$ increases the COF which confirms the statements made in Finding 3.

Since a mineral oil with higher viscosity (ISO VG-150) has been used in [6] a direct comparison of COF values is not possible. However, qualitative trends obtained are very 


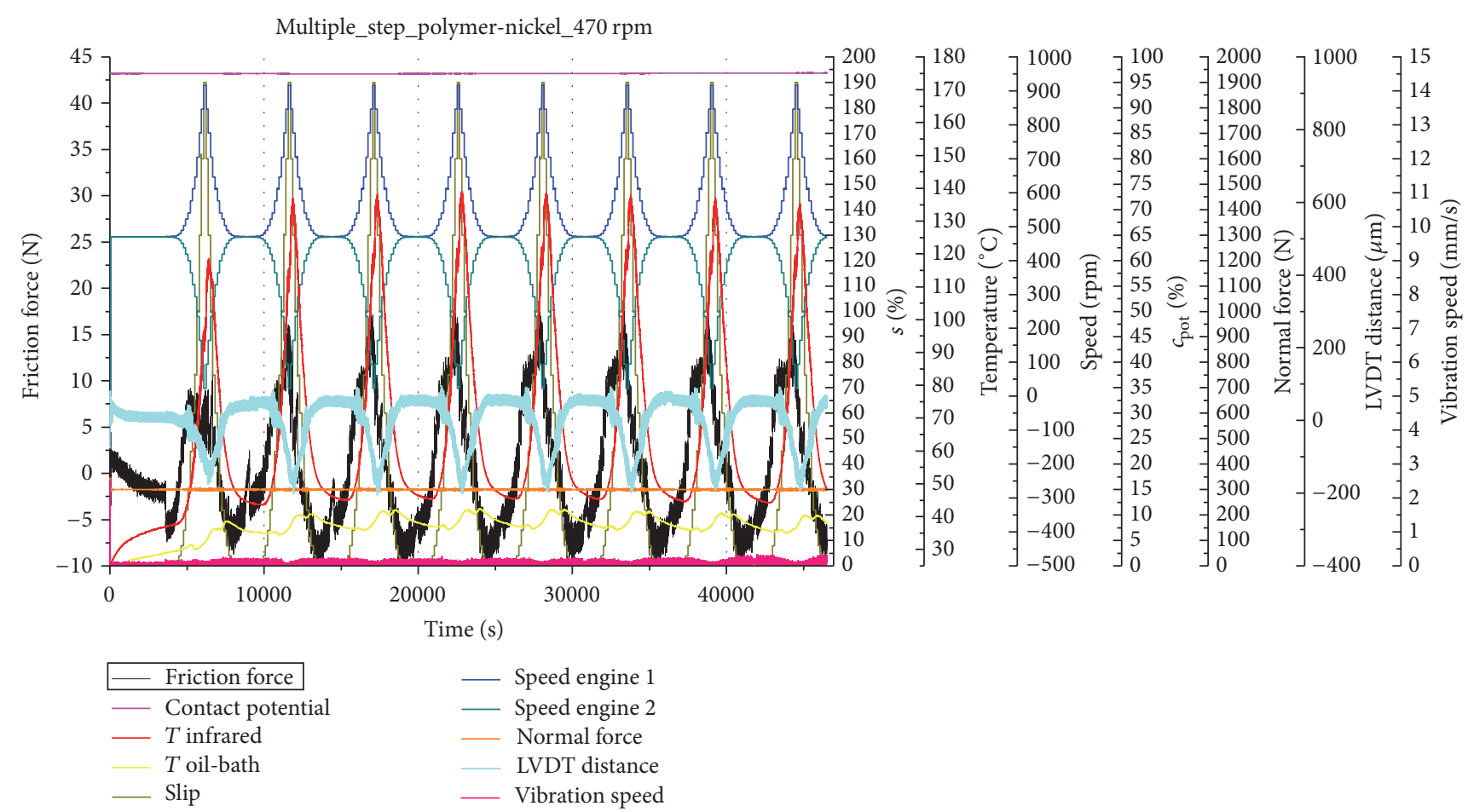

FIGURE 18: Results for a polymer-nickel coated experiment under dry conditions.

TABLE 4: Operating and material parameters for dry polymer-steel experiment.

\begin{tabular}{lc}
\hline$u_{m}=1.23 \mathrm{~m} / \mathrm{s}$ & $s=0-190 \%$ \\
$r_{1}=25 \mathrm{~mm}$ & $r_{2}=25 \mathrm{~mm}$ \\
$E_{1}=210 \mathrm{GPa}$ & $E_{2}=3 \mathrm{GPa}$ \\
$v_{1}=0.3$ & $v_{2}=0.3$ \\
$b_{1}=11 \mathrm{~mm}$ & $b_{2}=11 \mathrm{~mm}$ \\
$R_{a 1}=1.3 \mu \mathrm{m}$ & $R_{a 2}=1.8 \mu \mathrm{m}$ \\
$T_{0}=\mathrm{RT}$ & $p_{\max }=30 \mathrm{MPa}$ \\
\hline
\end{tabular}

similar. Also, the same trends are, for instance, observed in [21] even though a ball-on-disc tribotester was used.

3.4. Dry Polymer-Steel Experiments. High performance polymers, in combination with a metal counterpart, nowadays represent promising solutions for moderately loaded contacts under high sliding speed, whereby fully dry systems can be realised under certain conditions. Here, we present results of a polymer with polytetrafluoroethylene (PTFE) modification, rubbing against a $42 \mathrm{CrMo} 4 \mathrm{disc}$, which has been coated with a nickel-phosphor layer, performed under room temperature (RT). The corresponding material and operating parameters are listed in Table 4.

After an one-hour-lasting running-in phase eight slip cycles are carried out, which results in a total test time of twelve hours. Main findings are shown in Figure 18. Compared to the lubricated experiment high dependency of the infrared temperature, which reaches values of up to $135^{\circ} \mathrm{C}$, on the sliding speed can be examined. Due to the absence of oil, all heat has to be transferred through the discs. Furthermore, the signal of the LVDT distance sensor is correlating directly to the temperature signal; since the polymer suffers under a stiffness reduction at higher temperatures, deformations of up to $200 \mu \mathrm{m}$ can be measured.

Since polymers are electrically resistant, the contact potential is at its maximum value throughout the test.

The last three cycles of this experiment are depicted in Figure 19. One can note that at a temperature of $120^{\circ} \mathrm{C}$ the infrared temperature signal shows discontinuities at each cycle. After this event the friction is slightly decreasing, even though slip is raised further. The examined behaviour could be linked to phase changes of the polymer, most likely partial melting of PTFE. Also, due to thermal inertia, a time gap between the maximum of slip, which corresponds to maximum frictional power, and infrared temperature is detected in the graph.

Again, friction force and slip are postprocessed to a traction curve, which is depicted in Figure 20. Cycles five to eight are shown in this diagram.

Compared to the results shown in Figure 14 a hysteresis between the slip increase and decrease steps can be detected.

During the slip increase period local phase changes do occur, as indicated in Figure 19, leading to a self-lubricated system which reduces the COF during the slip decrease steps. Overall excellent reproducibility can be found again by comparison of the traction curves.

For a dry system, the measured friction is low, which can be attributed to the PTFE filling and also, the applied electroless nickel-phosphor coatings are known to have beneficial tribological effects when used with polymers [22, 23]. 

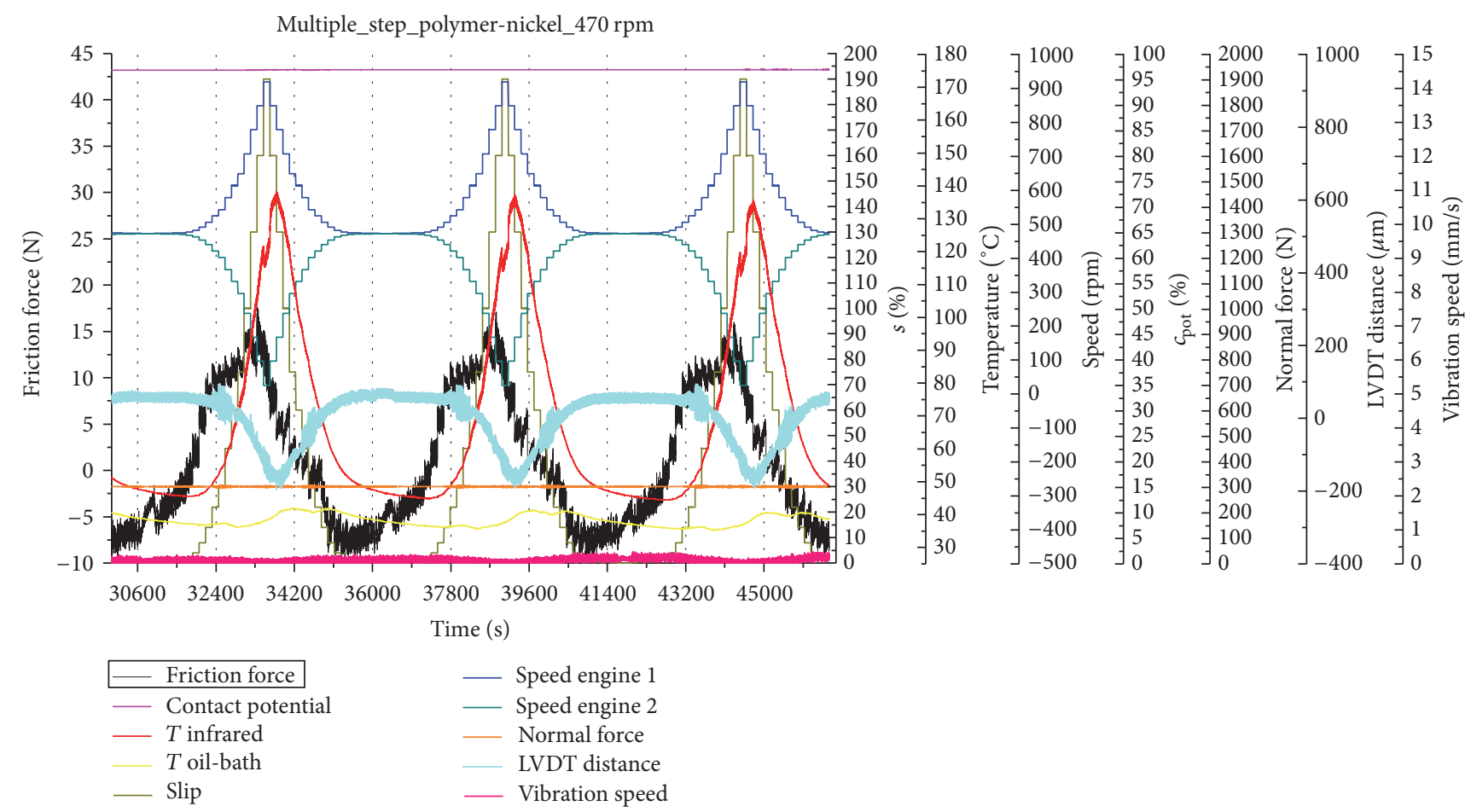

FIGURE 19: Results for a polymer-nickel coated experiment under dry conditions. Last three cycles.

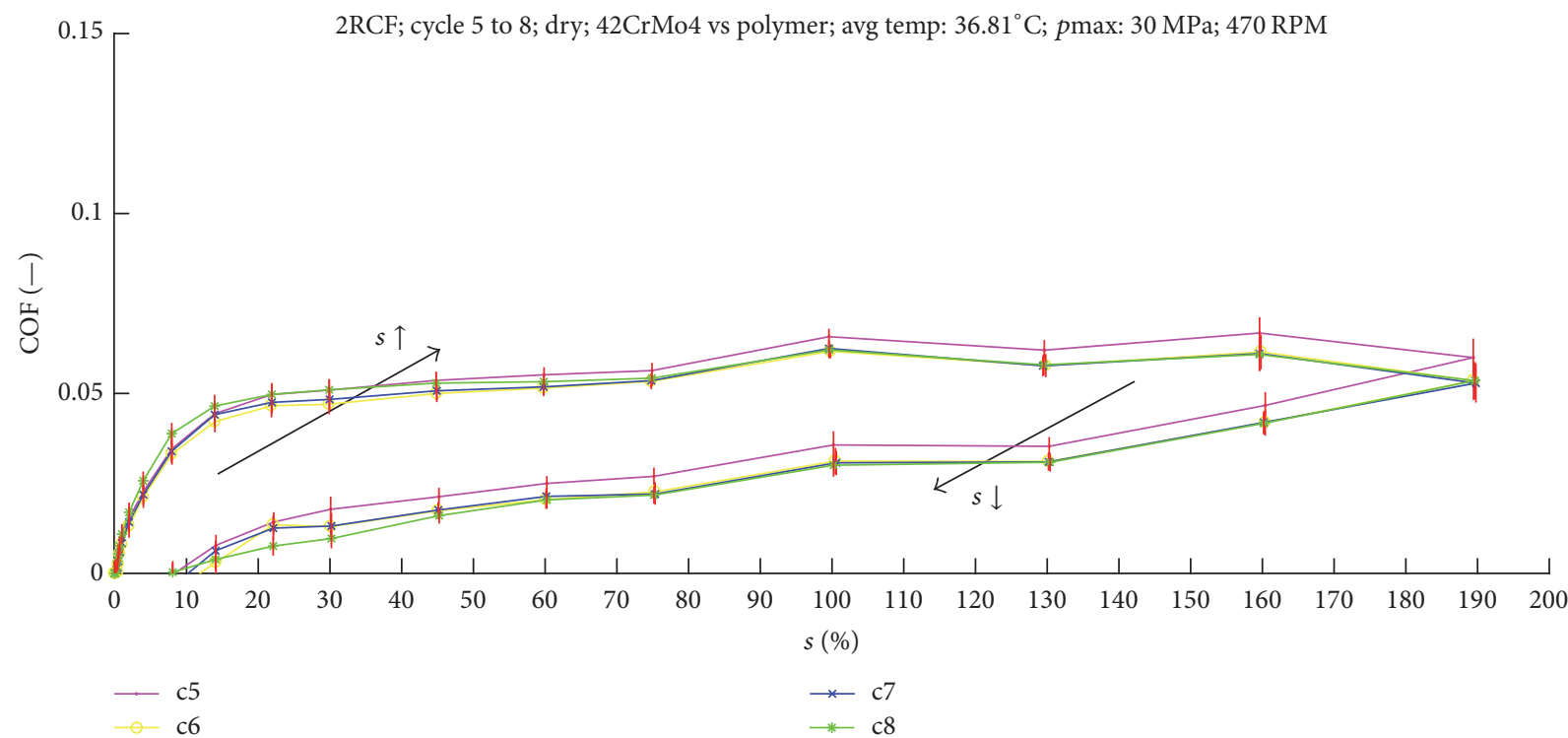

FIGURE 20: Traction curve for a polymer-nickel coated experiment under dry conditions.

3.5. High-Speed Data Measurements. To conclude this demonstration section, polar plots of measured signals are presented as a function of rotation angle. These measurements are transiently performed and logged periodically throughout the test at certain time steps. During one rotation of shaft 1 , positions and velocities of motors, friction force, contact potential, and vibration velocity are evaluated continuously in an array with 72 entries each, which means that data is available in steps of five degrees independent of the current speed and slip values. Figure 21 presents polar plots of friction force and vibration velocity for a polymer-steel experiment with conditions reported in Table 4 at a slip rate of seven percent.

An evenly distributed friction force along rotation angle can be concluded from this high-speed measurement, which indicates stationary friction conditions and therefore a good 


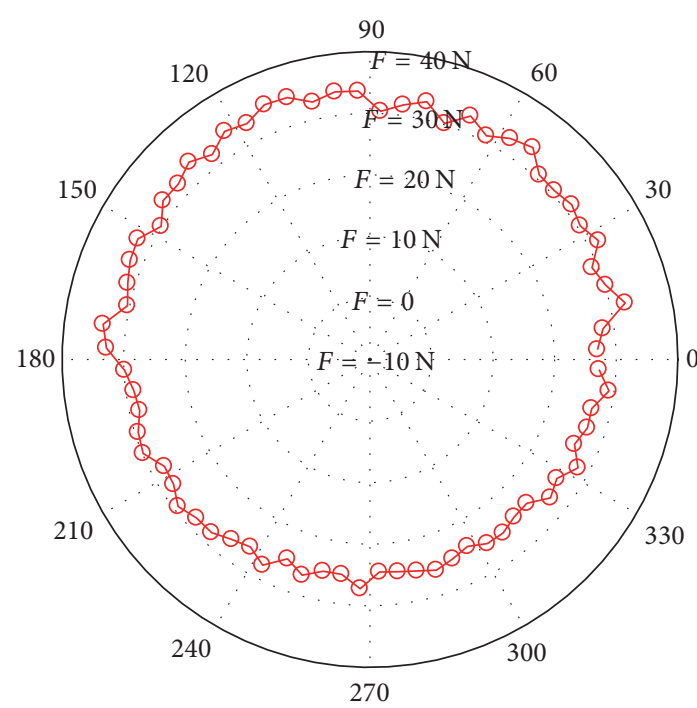

$\odot$ Friction force

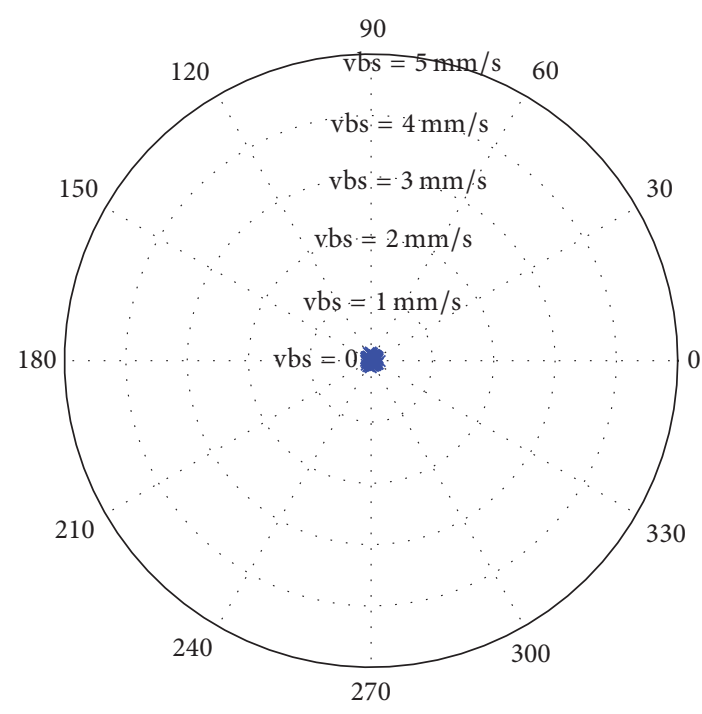

$*$ Vibration speed

(a)

(b)

FIGURE 21: Friction force (a) and vibration velocity (b) along one rotation of shaft 1 for $s=7 \%$.

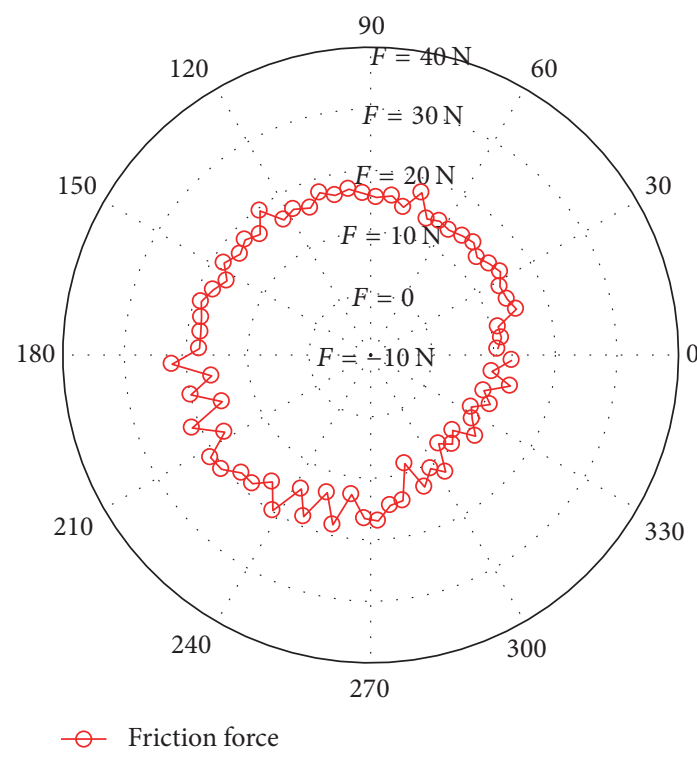

(a)

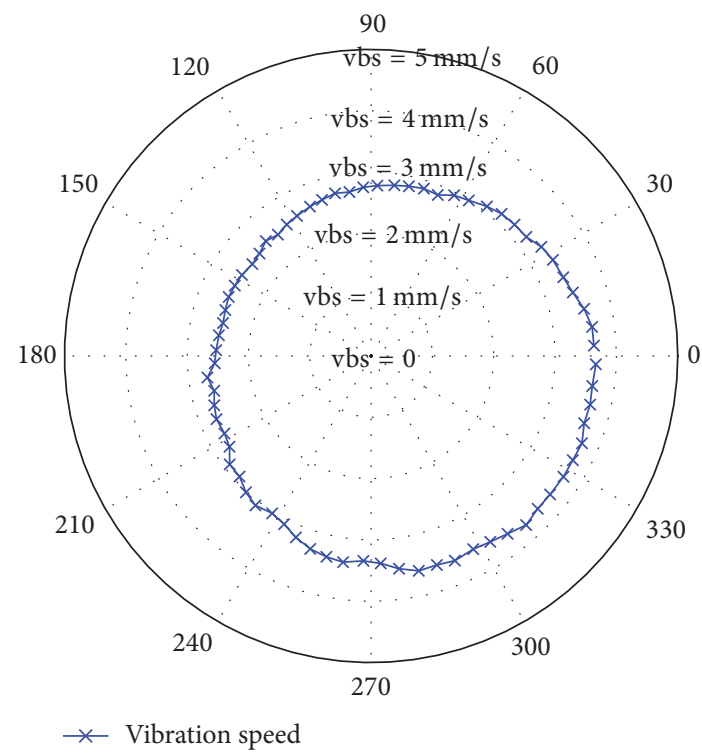

(b)

FiguRE 22: Friction force (a) and vibration velocity (b) along one rotation of shaft 1 for $s=0 \%$.

manufacturing quality of the specimens. The vibration velocity is close to zero, which indicates smooth test conditions as well.

Figure 22 depicts results of a polymer-steel high-speed measurement, whereby the polymer disc has experienced significant heat loads through high friction.

The damaged surface triggers significant vibrations of up to $3 \mathrm{~mm} / \mathrm{s}$ and the data is less homogeneously distributed along the rotating angle compared to Figure 21 . Note that this damage is hardly detectable by just considering the friction force, which emphasises the importance of vibration sensors and subsequent transient evaluation in two-disc machines.

Figure 23 shows images, obtained by an Olympus SZX12 light microscope, of the undamaged and damaged polymer specimens, used in the experiments shown in Figures 21 and 22 . While in the undamaged case only very mild wear, which occurs evenly distributed along the surface, can be detected, the damaged specimen shows localised loss of material. Note that the area above the white dashed line is filled with investment material. In this case the inhomogeneous material 


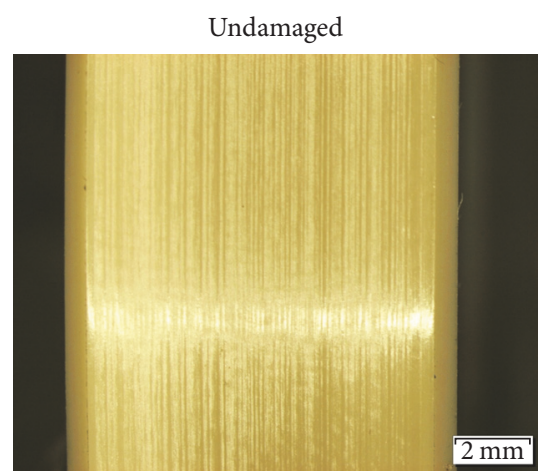

(a)

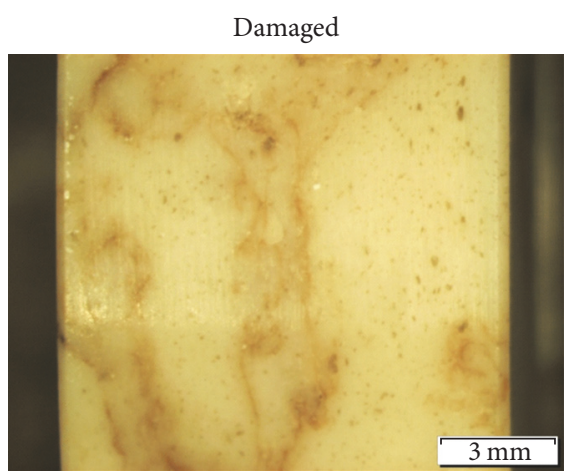

(b)

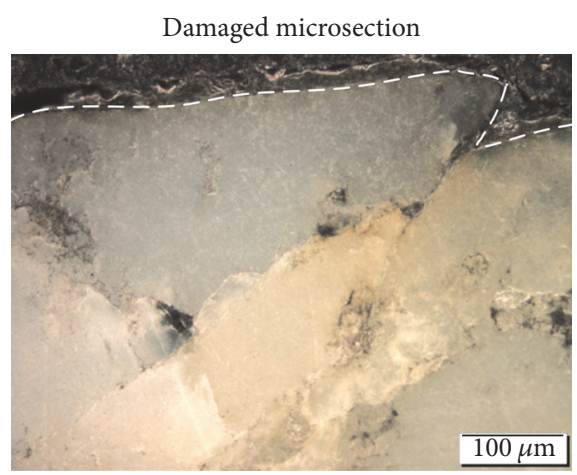

(c)

FIGURE 23: Microscopy images of undamaged and damaged polymer specimens. Overviews ( $\mathrm{a}$ and $\mathrm{b}$ ) and damaged microsection (c).

TABLE 5: Weight measurements of polymer specimens.

\begin{tabular}{lccc}
\hline Specimen & Initial weight & Final weight & Difference \\
\hline Undamaged & $22.61250 \mathrm{~g}$ & $22.59388 \mathrm{~g}$ & $0.01862 \mathrm{~g}$ \\
Damaged & $23.96540 \mathrm{~g}$ & $23.92409 \mathrm{~g}$ & $0.04131 \mathrm{~g}$ \\
\hline
\end{tabular}

distribution triggers stress concentrations which lead to a rupture of small particles, resulting in vibrations as measured in Figure 22.

The weight of the specimens before and after testing is measured with a 5-digit digital scale; results are presented in Table 5.

As expected the wear loss of the damaged specimen is higher. Due to the mild wear and the strong temperature dependence of polymers on the elastic modulus, no link between the weight loss and LVDT sensor measurements can be established. However, as already illustrated in Figure 22, local rupture of material can be detected by utilising the developed high-speed data acquisition method.

\section{Conclusions}

A new two-disc machine, which is capable of performing experiments under dry and lubricated conditions, is presented. Highly precise control of set values can be realised due to the usage of modern soft- and hardware. Experiments under lubricated and dry conditions are conducted, to emphasise the functionalities of the test rig. High-speed measurements are performed in order to gain additional insight into the local tribological changes during the test phase. The machine will be employed for further research in the area of friction reduction in highly loaded contacts, by investigating polymer materials, coatings, and alternative lubrication scenarios.

\section{Nomenclature}

$\dot{V}_{\text {in }}$ : Fluid flow rate injected by the nozzle in $\mathrm{ml} / \mathrm{min}$

$\eta$ : Kinematic viscosity in $\mathrm{mm}^{2} / \mathrm{s}$ $v_{1}, v_{2}$ : Poison's ratios of the discs

$b_{1}, b_{2}$ : Thickness of the discs mm

$c_{\text {pot }}: \quad$ Contact potential in $\%$

COF: Coefficient of friction, $\mathrm{COF}=F_{R} / F_{N}$

$E_{1}, E_{2}$ : Young's modulus of the discs $\mathrm{GPa}$

$F_{L}$ : $\quad$ Force measured by the friction force transducer in $\mathrm{N}$

$F_{N}$ : Normal force in $\mathrm{N}$

$F_{R}$ : $\quad$ Friction force in $\mathrm{N}$

$n_{1}, n_{2}$ : Rotational speed of bodies in $1 / \mathrm{min}$

$p_{\max }$ : Maximum Hertzian pressure in $\mathrm{GPa}$

$r_{1}, r_{2}$ : Radii of the investigated discs $\mathrm{mm}$

$s$, SRR: Slide-to-roll ratio, $s=\left(u_{1}-u_{2}\right) / u_{m}$

$s_{\text {LVDT }}$ : Distance measured by the LVDT distance sensor in $\mu \mathrm{m}$

$T_{0}$ : $\quad$ Set temperature ${ }^{\circ} \mathrm{C}$

$T_{I}$ : Temperature measured by the infrared sensor in ${ }^{\circ} \mathrm{C}$

$u_{1}, u_{2}$ : Velocity of the discs in $\mathrm{m} / \mathrm{s}$

$u_{m}: \quad$ Entrainment velocity $u_{m}=\left(u_{1}+u_{2}\right) / 2$

$v_{\mathrm{vbs}}$ : Speed measured by the vibration sensor in $\mathrm{m} / \mathrm{s}$.

\section{Conflicts of Interest}

The authors declare that there are no conflicts of interest regarding the publication of this paper.

\section{Acknowledgments}

Financial support by the Austrian Federal Government (in particular from Bundesministerium für Verkehr, Innovation und Technologie and Bundesministerium für Wissenschaft, Forschung und Wirtschaft) represented by Österreichische Forschungsförderungsgesellschaft $\mathrm{mbH}$ and the Styrian and the Tyrolean Provincial Government, represented by Steirische Wirtschaftsförderungsgesellschaft $\mathrm{mbH}$ and Standortagentur Tirol, within the framework of the COMET Funding Programme, is gratefully acknowledged. 


\section{References}

[1] H. E. Merritt, "Worm gear performance," Proceedings of the Institution of Mechanical Engineers, vol. 129, no. 1, pp. 127-194, 1935.

[2] Deutsches Institut für Normung, Din 3990-1, 1987, https://shop .austrian-standards.at/action/en/public/details/111662/DIN_ 3990-1_1987_12.

[3] H. Wittel, D. Muhs, D. Jannasch, and J. Voßiek, Roloff/Matek Maschinenelemente, Normung, Berechnung, Gestaltung; 21. vollständig überbearbeitete Auflage, Springer, 2013.

[4] A. Trausmuth, I. Godor, M. Stoschka, A. Dietrich, and W. Eichlseder, "Load-carrying capacity prediction of different plasma nitrided, case hardened and quenched specimens under rolling contact loading," in Proceedings of the European Conference on Tribology, 2011.

[5] A. Trausmuth, Rolling contact fatigue of nitrided, case-hardened and quenched specimens [Ph.D. thesis], Montanuniversität Leoben, 2012.

[6] A. Doleschel, Wirkungsgradberechnung von Zahnradgetrieben in Abhängigkeit vom Schmierstoff [Ph.D. thesis], Technische Universität München, 2003.

[7] K. Bobzin, T. Brögelmann, K. Stahl, K. Michaelis, J. Mayer, and M. Hinterstoißer, "Friction reduction of highly-loaded rolling-sliding contacts by surface modifications under elastohydrodynamic lubrication," Wear, vol. 328-329, pp. 217-228, 2015.

[8] G. Meneghetti, A. Terrin, and S. Giacometti, "A twin disc test rig for contact fatigue characterization of gear materials," Procedia Structural Integrity, vol. 2, pp. 3185-3193, 2016.

[9] O. Kreil, Einfluss der Oberflächenstruktur auf Druckverteilung und Schmierfilmdicke im EHD-Kontakt [Ph.D. thesis], Technische Universität München, 2008.

[10] S. Akbarzadeh and M. M. Khonsari, "Experimental and theoretical investigation of running-in," Tribology International, vol. 44, no. 2, pp. 92-100, 2011.

[11] M. Masjedi and M. M. Khonsari, “Theoretical and experimental investigation of traction coefficient in line-contact EHL of rough surfaces," Tribology International, vol. 70, pp. 179-189, 2014.

[12] J. Kleemola and A. Lehtovaara, "Experimental evaluation of friction between contacting discs for the simulation of gear contact," Lubrication Science, vol. 13, no. 1, pp. 13-20, 2007.

[13] H. Krampl, F. Grün, and I. Godor, "Numerical and experimental investigation of non-conformal lubricated contacts," in Proceedings of the Nordic Symposium on Tribology, 2012.

[14] J. Moder, H. Krampl, and F. Grün, "Tribological analysis of lubricated non-conforming contacts," in Proceedings of the ÖTG Symposium, 2014.

[15] SIEMENS, "SIMATIC HMI Devices, Operating Instructions," 2015.

[16] SIEMENS, "Simotion Scout TIA Configuration Manual," 2014.

[17] SIEMENS, "S120 Drive Functions Manual," 2015.

[18] SIEMENS, "1FT7 Synchronous Motors Operating Instructions," 2015.

[19] R. Gohar, Elastohydrodynamics, World Scientific, 2001.

[20] W. Habchi, P. Vergne, S. Bair, O. Andersson, D. Eyheramendy, and G. E. Morales-Espejel, "Influence of pressure and temperature dependence of thermal properties of a lubricant on the behaviour of circular TEHD contacts," Tribology International, vol. 43, no. 10, pp. 1842-1850, 2010.
[21] M. Björling, Friction in elastohydrodynamic lubrication [Ph.D. thesis], Luleå Tekniska Universitet, 2014.

[22] R. Parkinson, "Properties and applications of electroless nickel," 2001.

[23] P. Sahoo and S. K. Das, "Tribology of electroless nickel coatings-a review," Materials and Design, vol. 32, no. 4, pp. 1760-1775, 2011. 


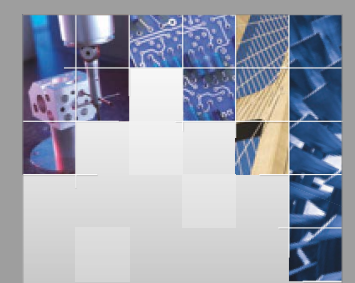

\section{Enfincering}
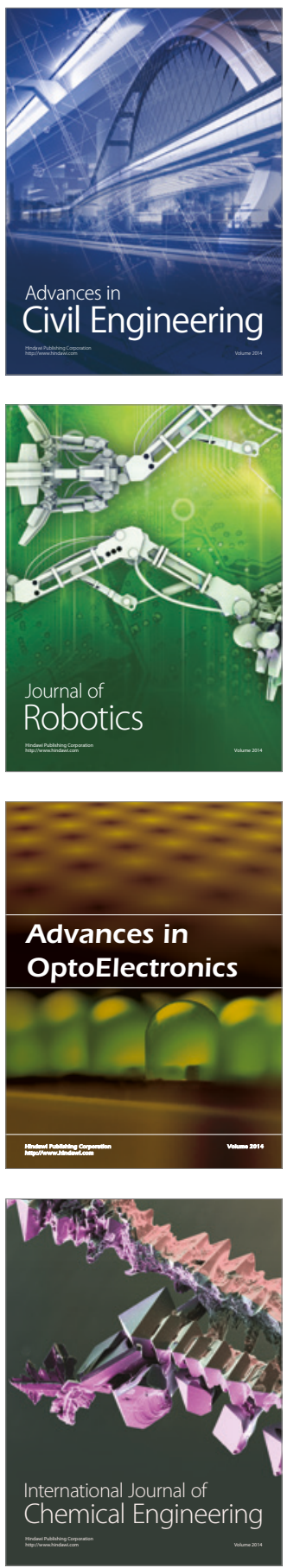

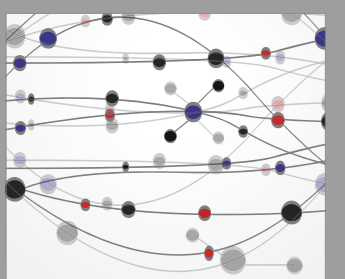

The Scientific World Journal

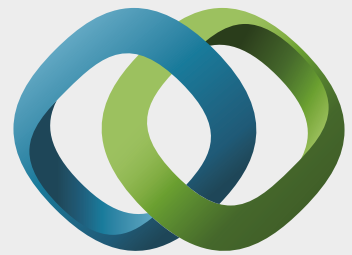

\section{Hindawi}

Submit your manuscripts at

https://www.hindawi.com
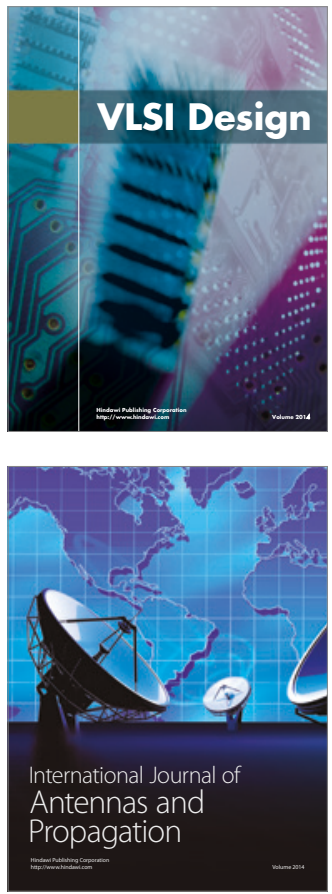

\section{Rotating}

Machinery
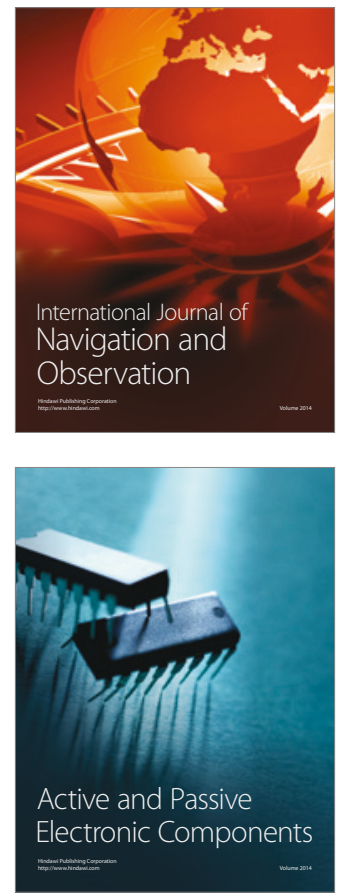
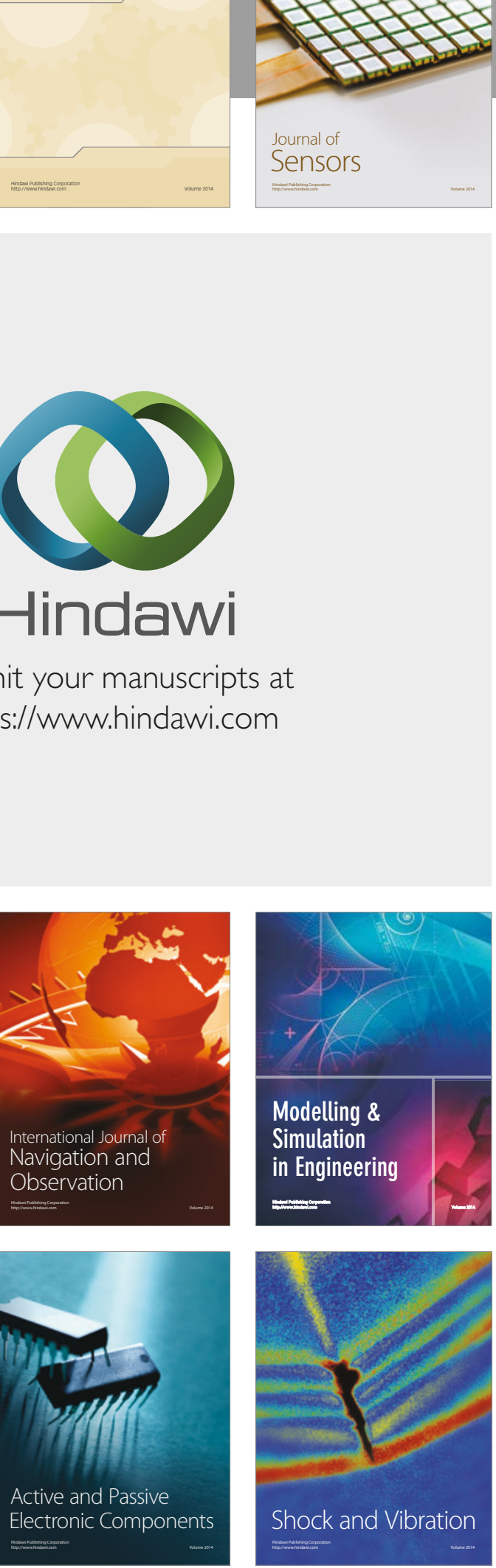
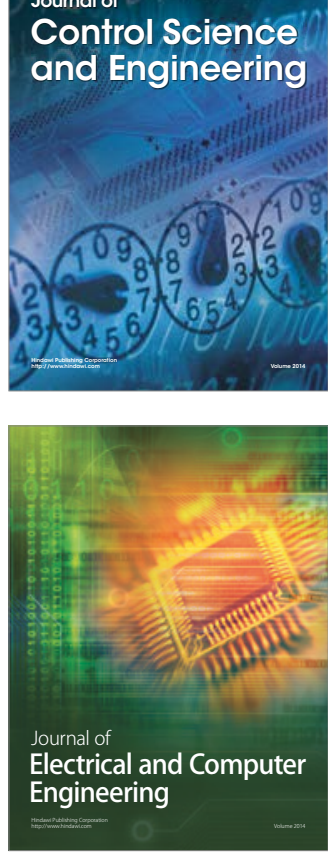

Distributed

Journal of

Control Science

and Engineering
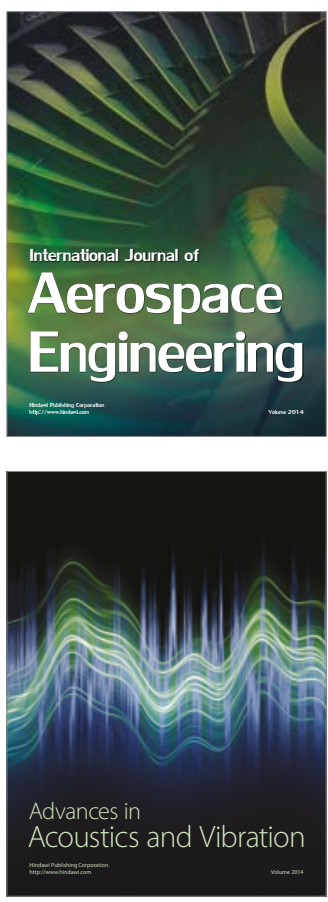

Sensor Networks 